\title{
Quantile-Dependent Heritability of Glucose, Insulin, Proinsulin, Insulin Resistance, and Glycated Hemoglobin
}

\author{
Paul T. Williams \\ Division of Molecular Biophysics \& Integrated Bioimaging, Lawrence Berkeley National Laboratory, \\ Berkeley, CA, USA
}

\section{Keywords}

Gene environment interaction · Glycemia · Heritability · Insulin · Adiposity

\begin{abstract}
Background: "Quantile-dependent expressivity" is a dependence of genetic effects on whether the phenotype (e.g., insulin resistance) is high or low relative to its distribution. Methods: Quantile-specific offspring-parent regression slopes $\left(\beta_{O P}\right)$ were estimated by quantile regression for fasting glucose concentrations in 6,453 offspring-parent pairs from the Framingham Heart Study. Results: Quantile-specific heritability $\left(h^{2}\right)$, estimated by $2 \beta_{\mathrm{OP}} /\left(1+r_{\text {spouse }}\right)$, increased $0.0045 \pm$ $0.0007\left(p=8.8 \times 10^{-14}\right)$ for each $1 \%$ increment in the fasting glucose distribution, that is, $h^{2} \pm$ SE were $0.057 \pm 0.021,0.095$ $\pm 0.024,0.146 \pm 0.019,0.293 \pm 0.038$, and $0.456 \pm 0.061$ at the 10th, 25th, 50th, 75th, and 90th percentiles of the fasting glucose distribution, respectively. Significant increases in quantile-specific heritability were also suggested for fasting insulin $\left(p=1.2 \times 10^{-6}\right)$, homeostatic model assessment of insulin resistance (HOMA-IR, $p=5.3 \times 10^{-5}$ ), insulin/glucose ratio $\left(p=3.9 \times 10^{-5}\right)$, proinsulin $\left(p=1.4 \times 10^{-6}\right)$, proinsulin/ insulin ratio $\left(p=2.7 \times 10^{-5}\right)$, and glucose concentrations during a glucose tolerance test $(p=0.001)$, and their logarithmically transformed values. Discussion/Conclusion: These findings suggest alternative interpretations to precision
\end{abstract}

karger@karger.com www.karger.com/lfg

Karger"

BOPEN ACCESS
(C) 2021 The Author(s)

Published by S. Karger AG, Basel

This is an Open Access article licensed under the Creative Commons Attribution-NonCommercial-4.0 International License (CC BY-NC) (http://www.karger.com/Services/OpenAccessLicense), applicable to the online version of the article only. Usage and distribution for commercial purposes requires written permission. medicine and gene-environment interactions, including alternative interpretation of reported synergisms between $A C E, A D R B 3, P P A R-\gamma 2$, and TNF- $a$ polymorphisms and being born small for gestational age on adult insulin resistance (fetal origin theory), and gene-adiposity (APOE, ENPP1, GCKR, IGF2BP2, IL-6, IRS-1, KIAA0280, LEPR, MFHAS1, RETN, TCF7L2), gene-exercise (INS), gene-diet (ACSL1, ELOVL6, IRS-1, PLIN, S100A9), and gene-socioeconomic interactions.

(C) 2021 The Author(s)

Published by S. Karger AG, Basel

\section{Introduction}

Hyperglycemia may be due to impaired insulin secretion from defective beta-cell function or mass, impaired insulin action, or both [1]. The risk of developing type 2 diabetes mellitus (T2DM) is $40 \%$ greater in 1 st-degree relatives of T2DM patients compared to the $4 \%$ risk in the general population [2]. Genetic and environmental risk factors are thought to interact to produce insulin secretary deficiency and resistance. The environmental risk factors for hyperglycemia and T2DM include adiposity, inactivity, poor prenatal nutrition, Western dietary patterns (high intakes of trans-fats, saturated fats, and sugar-sweetened beverages), and second-generation antipsychotic medication use [1].

Correspondence to:

Paul T. Williams, ptwilliams@lbl.gov 
Traditional estimates of heritability assume that genetic effects are the same throughout the phenotype distribution [3]. Quantile-dependent expressivity postulates that the effects of the genotype on the phenotype could depend on the level of the phenotype [4]. For example, this could be due to the genes affecting concentrationdependent enzymatic reactions, synthesis, and clearance. To test which is applicable, quantile regression can be used to fit offspring-parent or full-sib regression slopes separately to each quantile of the trait distribution [5]. Orthogonal polynomials can then test whether the quantile-specific slopes increase with increasing percentiles of the sample distribution [6]. Because quantile regression does not assume normality [5], the effect of the genotype is determined for the phenotype as originally measured (e.g., concentration, homeostatic model assessment [HOMA], or insulin/glucose ratio). Falconer's formula [3] is used to estimate quantile-specific heritability in the narrow sense $\left(h^{2}\right)$ from the quantile-specific regression slopes.

Interest in gene-environment interactions and genetic markers of treatment efficacy arises from the prospect for personalized medicine [7-10]. Epigenetic processes have been proposed as a molecular framework for environmental influences to affect gene expression and alter phenotypes via altered DNA methylation, covalent modifications of histone tails, and expression of miRNAs and other noncoding RNA [8]. Alternatively, the effects of genetic variants on phenotypes may simply depend on whether the phenotype (e.g., insulin resistance) is high or low relative to its distribution [4]. Prior analyses suggest that the heritability of total cholesterol [11], triglycerides [12], high-density lipoprotein cholesterol [13, 14], adiponectin [15], leptin [16], C-reactive protein concentrations [17], plasminogen activator inhibitor type-1 [18], adiposity [19], intakes of coffee and alcohol [20,21], and pulmonary function are quantile-dependent [22], whereas height $[4,19]$ and the intakes of other macronutrients are not [21]. Particularly compelling examples of quantiledependent expressivity are the decreases in cholesterol heritability following cholesterol lowering from statin use [11] and the increases in genetic effects when triglyceride concentrations are increased postprandially [23].

A potential consequence of quantile-dependent expressivity is the creation of apparent gene-environment interactions and precision medicine genetic markers [14]. This is because genetic effects will differ when subjects are selected for characteristics that distinguish high from low phenotype values (e.g., overweight vs. lean, sedentary vs. physically active, high- vs. low-fat diets). The interactions are frequently attributed to the aforementioned transcriptional or epigenetic processes when a simpler explanation of quantile-dependent expressivity may suffice. Purported genetic markers of drug efficacy may also be artifacts of quantile-dependent expressivity $[11,12]$. Consistency with quantile-dependent expressivity does not necessarily disprove the biological explanations suggested by others, nor gene-gene interactions or nonlinear effects. Rather, the phenomenon provides an alternative explanation for the interactions involved; that is, the fact that different genetic effects are observed simply because an environmental condition is associated with high or low phenotype values.

Whether quantile-dependent expressivity affects beta-cell function and insulin resistance phenotypes is currently unknown. Therefore, evidence for quantiledependent expressivity was sought by applying quantile regression [5] to sibships and offspring-parent pairs from the Framingham Study [24] to estimate heritability in the narrow sense $\left(h^{2}[3]\right)$ at different quantiles of the glucose, insulin, proinsulin, $\mathrm{HbAlc}$, homeostatic model assessment of insulin resistance (HOMA-IR), and HOMA-B distributions. Heritability was studied because only small proportions of fasting glucose and insulin variation are attributable to specific single nucleotide polymorphisms (SNP) [25], whereas additive genetic effects (i.e., heritability) represent approximately $49 \%$ of the variance of fasting insulin and $67 \%$ of the variance of fasting glucose concentrations [26]. The discussion is devoted to evaluating previous reports on glucose and insulin gene-environment interactions and precision medicine markers from the perspective of quantile-dependent expressivity to determine the concept's: (1) general applicability, (2) external validity, and (3) legitimacy using directly measured genotypes and alternative estimates of heritability.

\section{Methods}

The Framingham Study data were obtained from the National Institutes of Health FRAMCOHORT, GEN3, FRAMOFFSPRING Research Materials obtained from the National Heart, lung, and Blood (NHLBI) Biologic Specimen and Data Repository Information Coordinating Center. The hypothesis tested is exploratory and not considered as part of the initial Framingham Study design. The Framingham Study included 3 cohorts. The Original Framingham Cohort consisted of 5,209 men and women, aged 30-59 years, living in the town of Framingham, MA [27]. The Offspring Cohort consisted of 5,124 adult children of the original participants and their spouses who were 1st examined between 1971 and 1975, reexamined 8 years later, and then every $3-4$ years thereafter [24]. Children of the Offspring Cohort were recruited to form the Third Generation Cohort [28]. Subjects used in the current 
analyses were at least 16 years of age, were not taking medications for diabetes, and were self-identified as non-Hispanic white.

The study, including all methods and surveys, was approved by Boston University's Institutional Review Board and written informed consent, including consent for genetic analyses, was obtained for all study participants or parent and/or legal guardian if $<18$ years of age. All methods were carried out in accordance with all relevant guidelines and regulations. The anonymized data were provided to Lawrence Berkeley National Laboratory in accordance with the NHLBI Research Materials Distribution Agreement BioLINCC RMDA V02 1d20120806 for exclusive use to the principal investigator, Paul T. Williams, for data analysis and publication under his protocol "Quantile dependent penetrance." These analyses were approved by the Lawrence Berkeley National Laboratory Human Subjects Committee (HSC) for protocol "Gene-environment interaction versus quantile-dependent penetrance of established SNPs (107H021)." LBNL holds Office of Human Research Protections (Federalwide Assurance number FWA 00006253; approval number: 107H021-13MR20).

Casual plasma glucose levels in whole blood from the Original Cohort [29] were determined by the Somogyi-Nelson method [30]. Fasting plasma glucose was measured in fresh specimens from the Offspring Cohort with a hexokinase reagent kit (A-Gent Glucose Test; Abbott). Glucose assays were run in duplicate; the intra-assay coefficient of variation was $<3 \%$. HbAlc was measured by high-performance liquid chromatography after an overnight dialysis against normal saline to remove the labile fraction. The intra-assay and interassay coefficients of variation were $<2.5 \%$. The assay was standardized against the glycosylated hemoglobin assay used in the Diabetes Control and Complications Trial [31]. Two-hour post-challenge glucose levels were measured in fresh EDTA plasma following 75-g OGTT administered according to WHO standards [32] after a 12-h overnight fast.

Fasting insulin and proinsulin concentrations, having essentially no cross-reactivity to insulin split-products, were obtained on previously frozen $\left(-80^{\circ} \mathrm{C}\right)$ EDTA plasmas from the 7 th exam of the Offspring Cohort and the 1st exam of the Third Generation Cohort using the human insulin and proinsulin kits and protocols obtained from Linco Research (Linco Research, Inc., St. Charles, MO, USA). These were measured by the enzyme-linked immunosorbent assay in the Third Generation cohort and by radio-immunoassay in the 7th exam of the Offspring cohort. For the purposes of combining sibships and offspring-parent comparisons, the ELISA values were transformed to their radio-immunoassay equivalence using the formulas $y=1.557 x+38.886$ for insulin and $y=-0.003 x^{2}+1.027 x+3.977$ for proinsulin. The HOMA-IR was calculated as fasting insulin $(\mathrm{mIU} / \mathrm{mL}) \times$ fasting glucose $(\mathrm{mmol} /$ $\mathrm{mL}) / 22.5$, which is reported to be highly correlated $(r=0.98)$ with computer-derived HOMA-IR model estimated from the Framingham Study [33]. To convert insulin $\mathrm{pmol} / \mathrm{L}$ to $\mu \mathrm{U} / \mathrm{mL}$, pmol/L was divided by 6.945 , that is, $50 \mathrm{pmol} / \mathrm{L} / 6.945=7.199 \mu \mathrm{U} / \mathrm{mL}$.

\section{Statistics}

Age and sex adjustment was performed separately for each exam within the Original, Offspring, and Third Generation Cohorts using standard least-squares regression with the following independent variables: female $(0,1)$, age, age ${ }^{2}$, female $\times$ age, and female $\times$ age $^{2}$. Individual subject values were taken as the average of the residuals of the age and sex-adjusted concentrations over all available exams with no report of diabetic medication use. Average casual plasma glucose levels in whole blood were collected from exams 1-10 and 12-16 of the Original Cohort [29]. The Offspring Cohort's fasting glucose concentrations were calculated from the average of up to 7 measurements (exams 1-7), their HbAlc and 2 -h glucose OGTT concentrations from up to 2 measurements (exams 5 and 7), and their fasting insulin concentrations from 1 measurement (exam 7). For the Third Generation Cohort, fasting glucose concentrations were calculated from the average of up to 2 measurements (exams 1 and 2), fasting insulin from 1 measurement (exam 1), and their HbAlc and 2-h glucose OGTT concentrations from exam 2. Offspring-parent regression slopes $\left(\beta_{\mathrm{OP}}\right)$ were computed using parents from the Original Cohort (casual glucose only) and their children from the Offspring Cohort (fasting glucose), and using parents from the Offspring Cohort and their children from the Third Generation Cohort (fasting insulin and glucose, insulin/glucose ratio, proinsulin, proinsulin/insulin ratio, HOMA). Sibships were identified from the Offspring and Third Generation Cohorts. Full-sibling regression slopes $\left(\beta_{\mathrm{FS}}\right)$ for fasting glucose, insulin, and 2-h insulin and glucose were obtained by forming all $k_{i}\left(k_{i}-1\right)$ sibpair combinations for the $k_{i}$ siblings in sibship $i$ and assigning equal weight to each sibling [34].

Simultaneous quantile regression was performed using the sqreg command of Stata (version 11; StataCorp, College Station, TX, USA). Quantile-regression does not stratify the dataset but rather uses the entire dataset for estimating each quantile regression slope. One thousand bootstrap samples were drawn to estimate the variance-covariance matrix for the 91 quantile regression coefficients between the 5th and 95th percentiles of the offspring's distribution [35]. Post-estimation procedures (test and lincom) were used to test linear combinations of the slopes after estimation with $\Sigma k_{i}-2$ degrees of freedom for offspring-parent regression slopes and $\Sigma\left(k_{i}-1\right)$ degrees of freedom for sibship regression slopes, where $k_{i}$ is the number of offspring or siblings in family $i$, and the summation is taken of the $i, i=1 \ldots N$ families [34]. Quantile-specific expressivity was assessed by: (1) estimating quantilespecific $\beta$-coefficients $( \pm$ SE) for the 5 th, 6 th, $\ldots$, , 95 th percentiles of the sample distribution; (2) plotting the quantile-specific $\beta$ coefficient versus the quantile of the trait distribution; and (3) testing whether the resulting graph was constant, or changed as a linear, quadratic, or cubic functions of the percentile of the trait distribution using orthogonal polynomials [6]. Falconer and Mackay's formula equates heritability in the narrow sense $\left(h^{2}\right)$ to $h^{2}=2 \beta_{\mathrm{OP}} /$ $\left(1+r_{\text {spouse }}\right)$, where $r_{\text {spouse }}$ is the spouse correlation and $\beta_{\mathrm{OP}}$ is the offspring-parent regression slope, and to $h^{2}=\left[\left(1+8 \beta_{\mathrm{FS}} r_{\text {spouse }}\right)^{0.5}\right.$ $-1] / 2 r_{\text {spouse }}$ under specific restrictive assumptions where $\beta_{\mathrm{FS}}$ is the full sib regression slope [3]. "Quantile-specific heritability" refers to the heritability statistic, whereas "quantile-specific expressivity" is the biological phenomenon of the trait expression being quantiledependent.

\section{Results}

Sample sizes and sample characteristics are presented in Table 1. Table 2 shows that the traditional regression slopes between $\beta_{\mathrm{OP}}$ and $\beta_{\mathrm{FS}}$ were significant for all traits. Spouse correlation was generally weak for all 
Table 1. Sample characteristics, spouse correlation $\left(r_{\text {spouse }}\right)$, and traditional estimate of heritability $\left(h^{2}\right)$ in the narrow sense as estimated from $\beta_{\mathrm{OP}}$ and $\beta_{\mathrm{FS}}$ least-squares regression slopes, that is, $h^{2}=2 \beta_{\mathrm{OP}} /\left(1+r_{\text {spouse }}\right)$ and $h^{2}=[(1+$ $\left.\left.8 r_{\text {spouse }} \beta_{\mathrm{FS}}\right)^{0.5}-1\right] /\left(2 r_{\text {spouse }}\right)[3]$

\begin{tabular}{|c|c|c|c|c|c|}
\hline & \multicolumn{2}{|l|}{ Mean (SD) } & \multirow[t]{2}{*}{$r_{\text {spouse }}$} & \multicolumn{2}{|l|}{ Heritability $\left(h^{2}\right)$} \\
\hline & offspring & 3rd generation & & offspring-parent & full sib \\
\hline Fasting glucose, $\mathrm{mmol} / \mathrm{L}$ & $5.51(0.89)$ & $5.24(0.70)$ & 0.1676 & 0.1871 & 0.3019 \\
\hline Fasting insulin, pmol/L & $88.51(51.62)$ & 87.44 (32.09) & 0.0624 & 0.1342 & 0.4128 \\
\hline $\begin{array}{l}\text { Fasting insulin/glucose, pmol/ } \\
\mathrm{mmol}\end{array}$ & $0.88(0.46)$ & $0.93(0.31)$ & 0.0255 & 0.1607 & 0.3768 \\
\hline HOMA-IR & $3.76(2.86)$ & $3.44(1.58)$ & 0.0655 & 0.0914 & 0.3534 \\
\hline HOMA-B & $171.18(78.37)$ & $154.91(86.22)$ & 0.0238 & 0.1553 & 0.2819 \\
\hline Proinsulin, pmol/L & $14.76(12.94)$ & $12.28(7.53)$ & 0.1764 & 0.1076 & 0.2358 \\
\hline Proinsulin/insulin & $0.17(0.10)$ & $0.14(0.05)$ & 0.0898 & 0.1354 & 0.2010 \\
\hline OGTT glucose, $\mathrm{mmol} / \mathrm{L}$ & $6.39(2.55)$ & $5.75(1.69)$ & 0.0739 & 0.1395 & 0.2619 \\
\hline $\mathrm{HbA} 1 \mathrm{c}, \%$ & $5.45(0.74)$ & $5.43(0.40)$ & 0.0795 & 0.0970 & 0.3242 \\
\hline
\end{tabular}

Casual glucose concentrations averaged $4.99(1.19) \mathrm{mmol} / \mathrm{L}$ with $r_{\text {spouse }}=0.0268$. Offspring-parent analyses: number of offspring with 1 parent and 2 parents were 1,261 and 2,596, respectively, for fasting glucose, 1,107 and 2,173 for casual glucose, 1,620 and 1,298 for fasting insulin, 1,614 and 1,290 for fasting insulin/glucose and HOMAIR and HOMA-B, 1,746 and 1,277 for proinsulin, 1,602 and 1,165 for proinsulin/insulin ratio, 1,292 and 1,374 for OGT, and 1,464 and 1,310, respectively, for $\mathrm{HbA1c}$. Full-sib analyses: number of siblings and sibships were 6,030 and 2,151 , respectively, for fasting glucose, 4,342 and 1,611 for fasting insulin, 4,334 and 1,607 for fasting insulin/glucose and HOMA-IR and HOMA-B, 4,486 and 1,652 for proinsulin, 4,129 and 1,543 for proinsulin/insulin ratio, 4,046 and 1,531 for OGTT, and 4,102 and 1,541, respectively, for HbA1c. HOMA, homeostatic model assessment; HOMA-IR, homeostatic model assessment of insulin resistance; $\beta_{\mathrm{FS}}$, full-sibling regression slopes; $\beta_{\mathrm{OP}}$, offspring-parent regression slopes.

phenotypes except fasting glucose and proinsulin concentrations. Heritability in the narrow sense was generally stronger when estimated from $\beta_{\mathrm{FS}}$ than $\beta_{\mathrm{OP}}$, and generally stronger for logarithmically transformed data.

\section{Quantile-Dependent Expressivity}

Figure 1a presents the quantile-specific $\beta_{\mathrm{OP}}$ for ageand sex-adjusted fasting glucose concentrations at the 10th, 25th, 50th, 75th, and 90th percentiles of the offspring's distribution. The slopes, which theoretically approximate one-half the heritability at each percentile $\left[h^{2}=2 \times \beta_{\mathrm{OP}} /\left(1+r_{\text {spouse }}\right)\right]$, get progressively steeper with increasing percentiles of the trait's distribution. $\beta_{\mathrm{OP}}$ at the 90 th percentile was 8 -fold greater than at the 10 th percentile, and their $\beta_{\mathrm{OP}}$ difference was highly significant $(0.233$ $\pm 0.036, p=5.8 \times 10^{-11}$, Table 2). These selected slopes were combined with those of the other percentiles between the 5th and 95th percentiles to create the quantile-specific heritability plot in Figure 1b. They show a significant linear trend for increasing heritability with increasing percentiles of the fasting glucose distribution (i.e., slope \pm SE: $\left.0.0044 \pm 0.0007, p=8.8 \times 10^{-14}\right)$. The graph also exhibits significant nonlinearity (quadratic: $p=3.9 \times 10^{-5}$, cubic: $p=0.01$ ), culminating in the strongest heritability at the highest percentiles. The $\beta_{\mathrm{OP}}$ were individually significant $(p<0.05)$ for all percentiles between the 7 th and 95 th percentiles of the offspring' distribution. Table 2 shows that the linear increase in $\beta_{\mathrm{OP}}$ by percentiles of the trait distribution was also significant for log-transformed fasting glucose.

Figure $2 \mathrm{a}$ shows that nearly identical results were obtained when comparing the fasting glucose concentrations in the Offspring Cohort to their parent's casual blood sugar measurements in the Original Cohort (replication). Figure $2 \mathrm{~b}$ suggests that fasting glucose concentrations in full sibs also show quantile-dependent expressivity, that is, increasing quantile-specific $\beta_{\mathrm{FS}}$ with increasing percentiles of the sibling distribution, with significant convexity culminating with the greatest estimated heritability at the highest percentiles of the distribution. Again, quantile-specific $\beta_{\mathrm{FS}}$ were significant at $p<0.05$ for all individual percentiles between the 9th through the 95th percentiles.

Figures 3 and 4 show that $\beta_{\mathrm{OP}}$ and $\beta_{\mathrm{FS}}$ both increased significantly with increasing percentiles of the fasting 


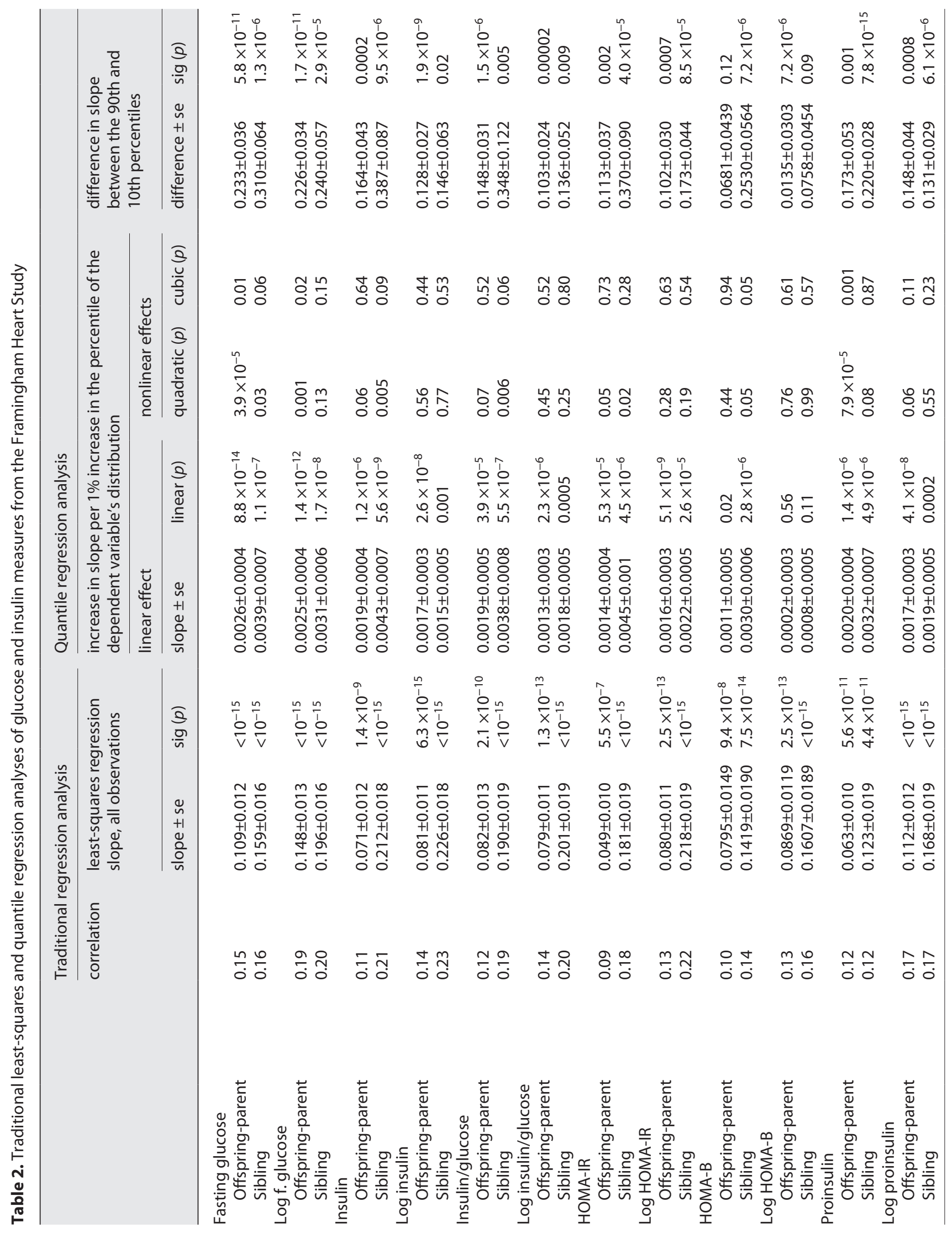




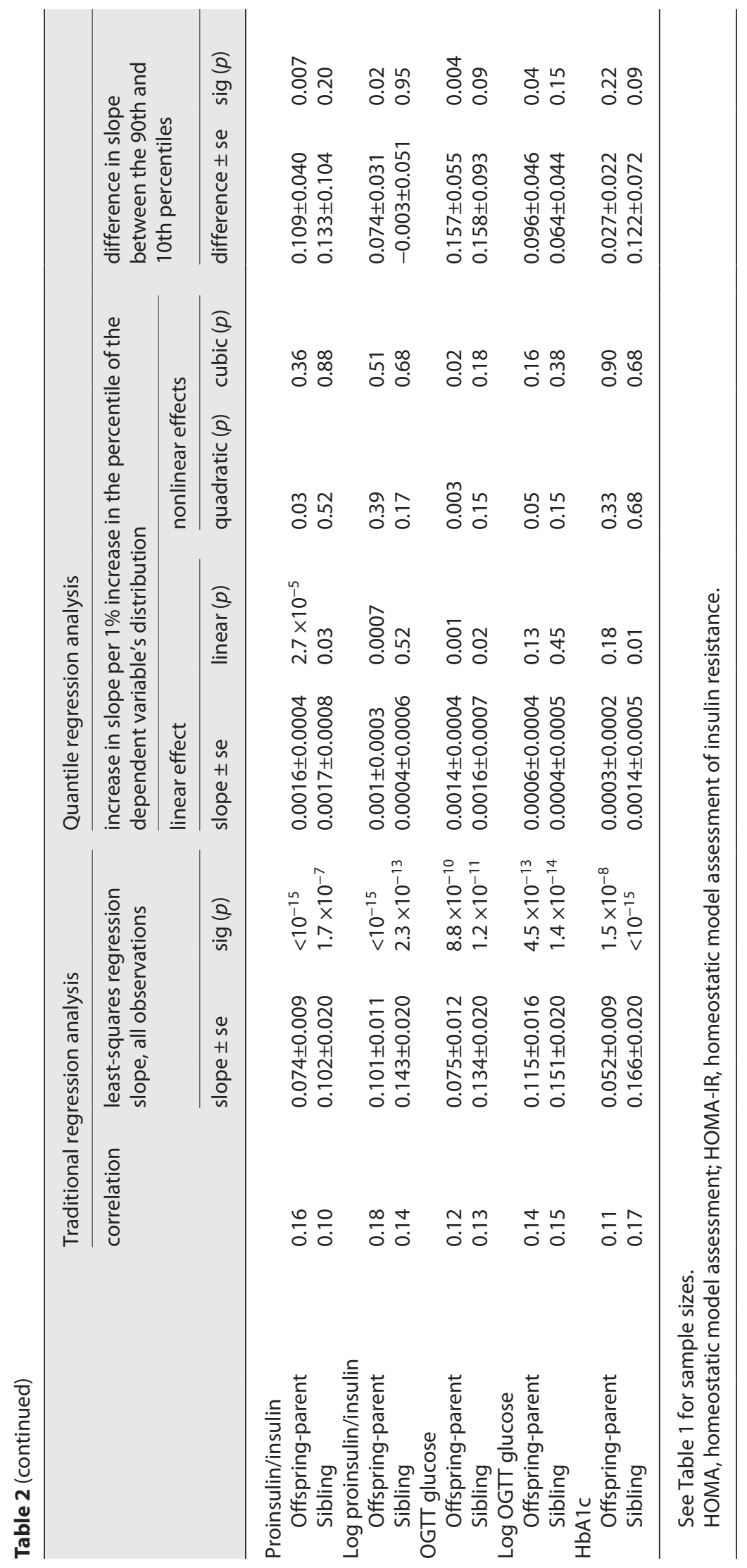




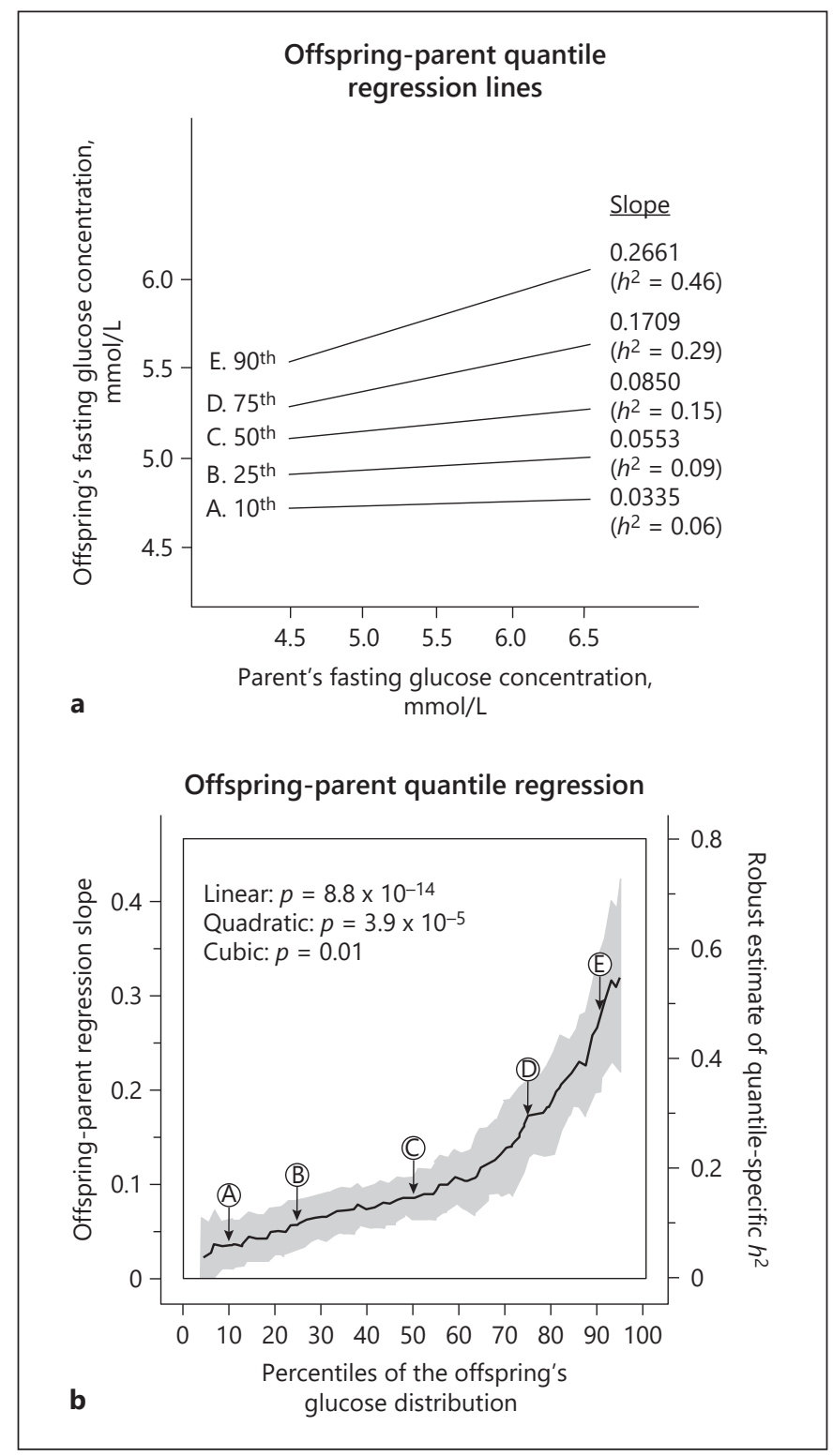

Fig. 1. a $\beta_{\mathrm{OP}}$ for selected quantiles of the offspring's fasting glucose concentrations, with corresponding estimates of heritability $\left[h^{2}=\right.$ $\left.2 \beta_{\mathrm{OP}} /\left(1+r_{\text {spouse }}\right)\right]$. The slopes became progressively greater (i.e., steeper) with increasing quantiles of the glucose distribution. $\mathbf{b}$ The 10 th, 25th, 50th, 75th, and 90th quantile-specific regression slopes were included with those of other quantiles to create the quantilespecific heritability function. Significance of the linear, quadratic, and cubic trends and the 95\% confidence intervals (shaded region) determined from 1,000 bootstrap samples. $\beta_{\mathrm{OP}}$, offspring-parent regression slope.

insulin, HOMA-IR, HOMA-B, OGTT glucose and the proinsulin/insulin ratio distributions. Additionally, Table 2 shows that both $\beta_{\mathrm{OP}}$ and $\beta_{\mathrm{FS}}$ increased with increasing proinsulin concentrations. The significant linear trends

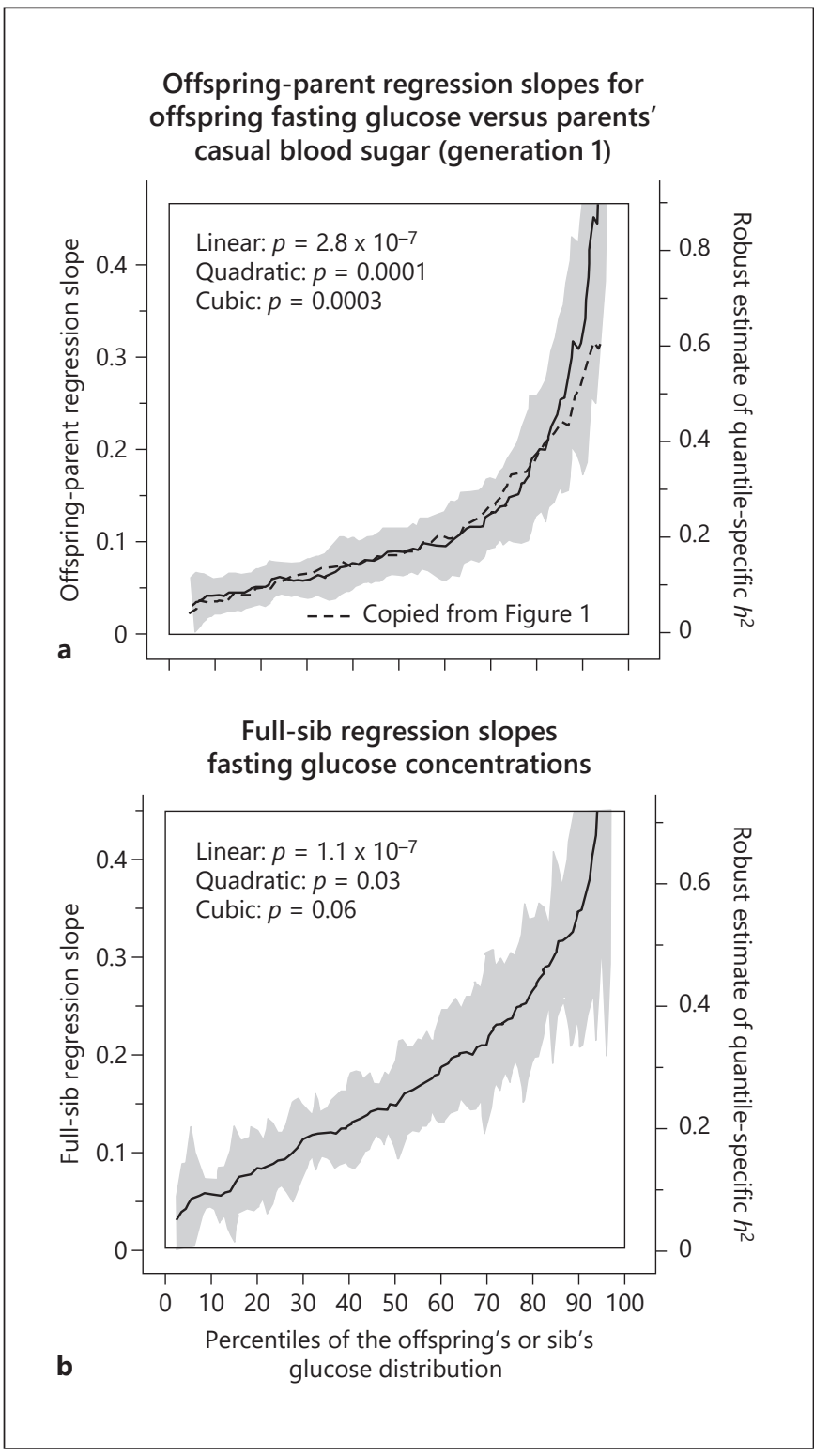

Fig. 2. a $\beta_{\mathrm{OP}}$ of fasting glucose concentrations from the Offspring Cohort versus casual glucose concentrations from the Original Framingham cohort (solid line). When compared to the dashed line copied from Figure 1b, it shows nearly identical results for the 2 generations, and little difference between using fasting or casual glucose measurements for the parent's values. b $\beta_{\mathrm{FS}}$ versus quantiles of the sib's glucose distribution. Significance of the linear, quadratic, and cubic trends and the 95\% confidence intervals (shaded region) determined from 1,000 bootstrap samples. $\beta_{\mathrm{FS}}$, full-sibling regression slope; $\beta_{\mathrm{OP}}$, offspring-parent regression slope.

in $\beta_{\mathrm{OP}}$ and $\beta_{\mathrm{FS}}$ were maintained for the log-transformed data except the proinsulin/insulin ratio, glucose OGTT, and HOMA-B. Quantile-dependence was less supported for $\mathrm{HbA} 1 \mathrm{c}$.
16

Lifestyle Genomics 2022;15:10-34 DOI: $10.1159 / 000519382$
Williams 
Fig. 3. $\beta_{\mathrm{OP}}$ and $\beta_{\mathrm{FS}}$ regression slopes versus quantiles of the offspring's distribution for fasting insulin concentrations $(\mathbf{a}, \mathbf{b})$, HOMA-IR (c, d), and HOMA-B (e, f). Significance of the linear, quadratic, and cubic trends and the 95\% confidence intervals (shaded region) determined from 1,000 bootstrap samples. HOMA, homeostatic model assessment; HOMA-IR, homeostatic model assessment of insulin resistance; $\beta_{\mathrm{FS}}$, fullsibling regression slope; $\beta_{\mathrm{OP}}$, offspring-parent regression slope

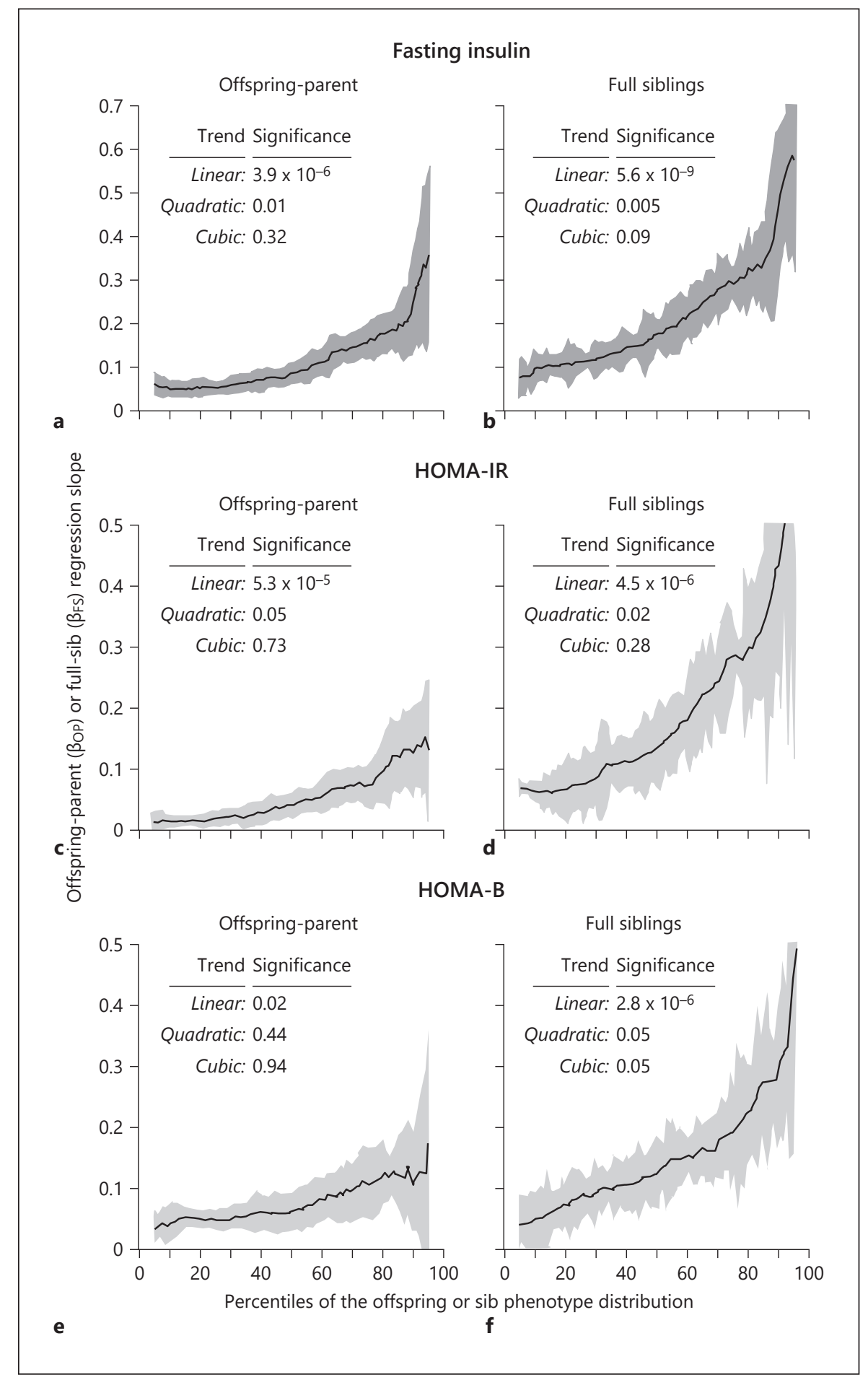

\section{Discussion}

Our analyses suggests that the heritability of fasting glucose in the narrow sense increases with increasing percentiles of its distribution, and accelerates significantly at the highest percentiles, that is, the portion of the distribution most affected by insulin resistance and beta-cell dysfunction (Fig. 1). These results were replicated using the casual glucose samples of the Original Framingham Cohort despite the substantial differences in age and visit 
Fig. 4. $\beta_{\mathrm{OP}}$ and $\beta_{\mathrm{FS}}$ regression slopes versus quantiles of the offspring's distribution for percent $\mathrm{HbAlc}(\mathbf{a}, \mathbf{b})$, oral glucose tolerance test (OGTT) 2-h glucose concentrations (c, d), and proinsulin/insulin ratio $(\mathbf{e}, \mathbf{f})$. Significance of the linear, quadratic, and cubic trends and the $95 \%$ confidence intervals (shaded region) determined from 1,000 bootstrap samples. $\beta_{\mathrm{FS}}$, full-sibling regression slopes; $\beta_{\mathrm{OP}}$, offspring-parent regression slopes
HbA1c
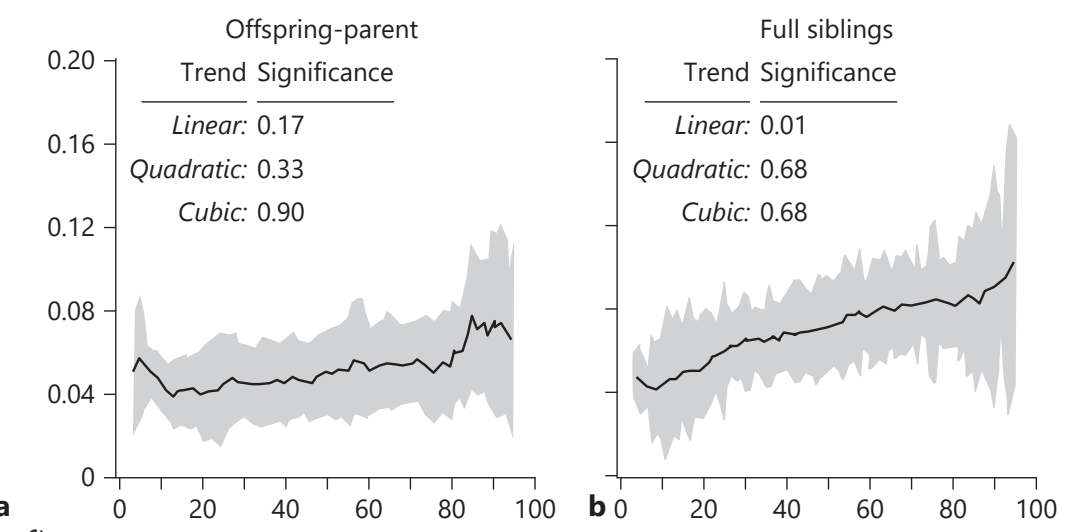

c

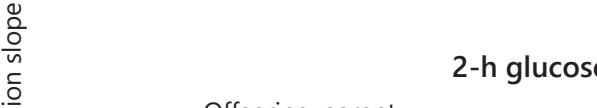

-h glucose
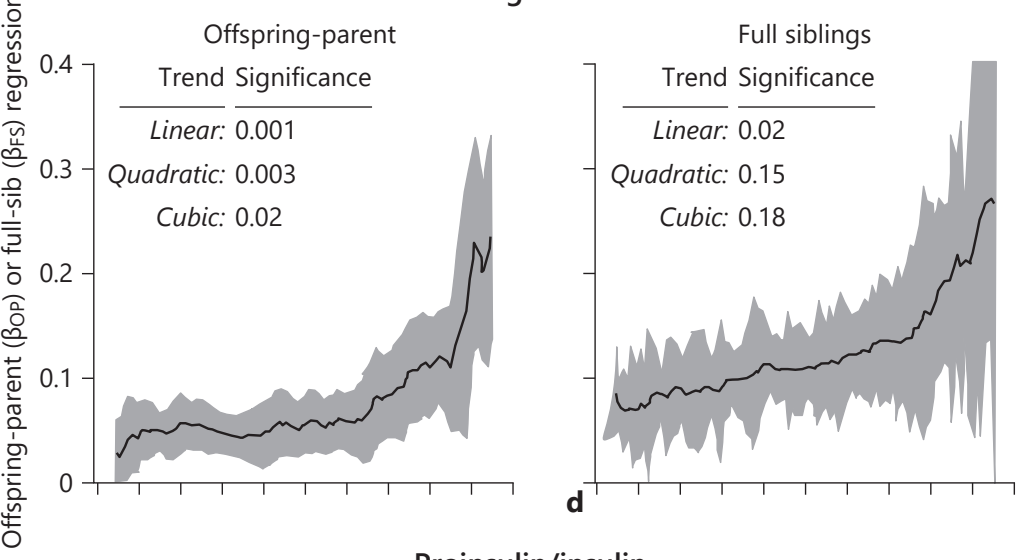

Proinsulin/insulin
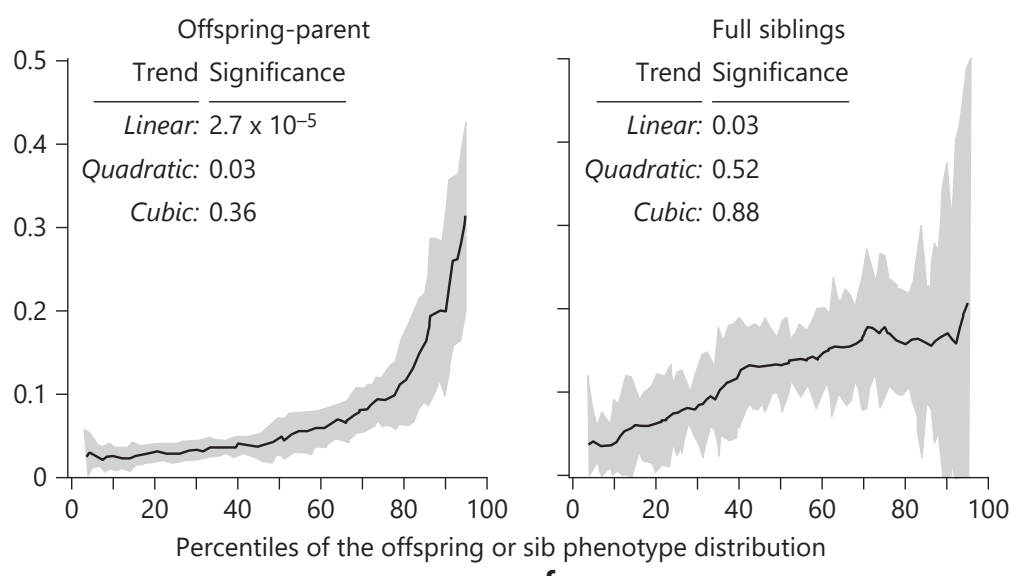

e number (Fig. 2a). Heritability $\left(h^{2}\right)$ estimated from $\beta_{\mathrm{FS}}$ yielded a similar finding (Fig. 2b). Significant increases in quantile-specific $h^{2}$ persisted when fasting glucose values were logarithmically transformed (Table 2). Significant quantile-dependent expressivity was also suggested for fasting insulin and proinsulin concentrations, the insulin/glucose ratio, HOMA-IR, and their logarithmic transformations (Table 2; Fig. 3, 4). An elevated proinsulin/ 
insulin ratio due to a disproportionate proinsulin release of from beta cells may be a marker of islet dysfunction [36], whereas fasting insulin, insulin/glucose ratio, and HOMA-IR may primary reflect insulin resistance. Collectively, these results are consistent with the hypothesis that the genetic inheritances of glycemia, beta-cell function, and insulin resistance are quantile-dependent. The larger heritability estimates calculated from full sib than offspring-parent pairs could be due to environmental confounding, generational differences, or genetic dominance effects.

Quantile-specific heritability was similar for HOMAIR and HOMA-B. HOMA-IR relates to genetic influences affecting insulin resistance (i.e., decrease in insulin mediated glucose disposal in insulin-sensitive tissue and increased hepatic glucose production) and HOMA-B to beta cell dysfunction (i.e., inability of beta-cells to compensate for the insulin resistance) [37]. Impaired $\beta$-cell function may occur several years after the onset of insulin resistance in skeletal muscle tissue, and may in fact increase before steeply declining 3 or 4 years prior to the onset of diabetes [38].

Important caveats to our analysis of phenotypes in family sets are: (1) heritability lacks the specificity of directly measured genotypes even if it is a more inclusive measure of genetic effects; and (2) Falconer's formula probably do not adequately address the true complexity of the genetics and shared environment affecting glycemia. These concerns can be partly addressed by reanalyzing published studies from the perspective of quantiledependent expressivity. These are studies that differed from our analyses in that they measured genetic variants directly, or they used alternative estimates of heritability. They include multiple examples where a paper's interpretation from the perspective of precision medicine or gene-environment interactions might be more simply explained by a single common phenomenon: quantiledependent expressivity. Particularly persuasive are those examples where the genetic effect size is reduced when the average phenotype level is decreased experimentally. Results are presented \pm SE.

\section{Precision Medicine}

Precision medicine seeks to individualize drug prescriptions by using genetic markers to target patients most likely to benefit from treatment [9]. Alternatively, quantile-dependent expressivity postulates that genetic markers follow different trajectories due to smaller genetic effects at lower glucose, insulin, or HbAlc concentrations. It is unnecessary under quantile-dependent

Quantile-Specific Inheritance of Glycemia expressivity to hypothesize biological interactions between genetic markers and treatment, rather the proposed markers are simply genetic signals that track changing heritability with changing mean concentrations.

\section{Antipsychotic Medications}

For example, olanzapine and risperidone are 2ndgeneration antipsychotics used in the treatment of schizophrenia spectrum disorders with the potential of inducing glucose intolerance. Kuzman et al. [39] reported that TT homozygotes of the 5 - $H$ T2C (serotonin $2 \mathrm{C}$ receptor) -759CT polymorphism experienced significantly greater 3 -month increases in fasting glucose concentrations than $\mathrm{C}$-allele carriers $\left(p_{\text {interaction }}=0.05\right)$. In particular, the histogram in Figure $5 \mathrm{a}$ (insert) shows greater increases specifically for the olanzapine-treated patients who were TT homozygotes $(1.72 \mathrm{mmol} / \mathrm{L})$ than carriers of the C-allele $\left(0.33 \mathrm{mmol} / \mathrm{L}, p_{\text {interaction }}=0.02\right)$. Two polymorphisms of the MDR1 (multidrug resistant protein) also interacted significantly with treatment response. Figure 5b's histogram shows that antipsychotic-treated patients who were TT homozygous for the MDR1 G2677T polymorphism had significantly greater increases in glucose $(0.98$ $\mathrm{mmol} / \mathrm{L})$ than the GT $(0.35 \mathrm{mmol} / \mathrm{L})$ or GG genotypes $\left(0.28 \mathrm{mmol} / \mathrm{L}, p_{\text {interaction }}=0.001\right)$. Figure $5 \mathrm{c}^{\prime} \mathrm{s}$ histogram shows significantly greater increases in fasting glucose in olanzapine-treated patients who were TT homozygotes than carriers of the C-allele of the MDR1 3435CT polymorphism $\left(p_{\text {interaction }}=0.03\right)$. However, overall fasting glucose concentrations increased from $4.80 \pm 0.05$ at baseline to $5.20 \pm 0.12 \mathrm{mmol} / \mathrm{L}$ after 3 -month antipsychotic treatment. The line-graphs in Figure $5 \mathrm{a}-\mathrm{c}$ show the genotype-specific increases were possibly the effects of quantile-dependent expressivity in association with the treatment-induced increase in average glucose concentrations. In particular, the smaller genetic effect size at the lower (pretreatment) than higher (post-treatment) average glucose concentrations requires that the trajectories of the glucose increases cannot move in parallel for different genotypes when glucose concentrations are increased pharmacologically. Subtracting the pretreatment from the post-treatment glucose levels will necessarily require a relatively greater increase for the genotype with the higher pretreatment glucose level vis-à-vis the genotype with the lower pretreatment level.

\section{Anti-Diabetic Medication}

Repaglinide belongs to the meglitinide class of shortacting insulin secretagogues that stimulates insulin release. He et al. [40] reported that reductions in HbAlc 
from repaglinide treatment differed significantly by KCNJ11 E23K genotypes ( $p=0.02$, Fig. 6a histogram), such that the significant pretreatment $\mathrm{HbA1c}$ differences between genotypes $(p=0.01)$ became nonsignificant on treatment ( $p=0.56$, Fig. 6a line graph). Quantiledependent expressivity would attribute at least some of the difference in treatment response to the larger pretreatment genetic effect size when average $\mathrm{HbAlc}$ was high (mean \pm SE: $8.31 \pm 0.14 \%$ ) versus smaller posttreatment genetic effect size when average $\mathrm{HbAlc}$ was reduced $(6.24 \pm 0.07 \%)$.

Pioglitazone is an insulin-sensitizing thiazolidinedione that binds with the peroxisome proliferators-activated receptor- $\gamma 2(P P A R-\gamma 2)$ gene to activate transcription of genes involved with glucose and lipid metabolism. Pei et al. [41] reported that CG heterozygotes of the rs1801282 polymorphism showed significantly greater reductions in fasting glucose concentrations than CC homozygotes ( $p=0.02$, Fig. 6b histogram) which quantile-dependent expressivity would attribute to the greater cross-sectional difference between genotypes before treatment when average fasting glucose was high versus the smaller crosssectional genotype difference after treatment when average fasting glucose was low (Fig. 6b line graph).

Metformin inhibits hepatic glucose production, and is the most widely prescribed 1st-line drug for treating T2DM. The heritability of metformin's glycemic response is estimated to be about 34\% [42]. Díaz et al. [43] reported that metformin produced changes in fasting insulin concentrations that were significantly related to a genetic risk score (GRS) derived from the OCT1, STK11, FTO, $S H B G$, and $A R$ genes after 1 year $\left(p_{\text {interaction }}=0.004\right)$ in hyperandrogenic adolescent girls. The score was significantly related to insulin concentrations prior to treatment $(p=0.03)$ but not after treatment began $(p=0.35)$, which may be due in part to quantile-dependent expressivity and the higher pretreatment than on-treatment insulin

Fig. 5. Histograms present the precision medicine interpretation of Kuzman et al.'s [39] report showing the mean glucose increase by genotype following 3-month antipsychotic treatment. Line graphs present a quantile-dependent expressivity interpretation where a larger post-treatment genetic effect size occurs when the average glucose concentration was high versus a smaller pretreatment genetic effect size when the average glucose concentration was low, requiring nonparallel glucose increases by genotype for: 5-HT2C (serotonin 2C receptor) -759CT polymorphism in olanzapine-treated patients $\left(p_{\text {interaction }}=0.02\right)(\mathbf{a}) ; M D R 1$ G2677T polymorphism in olanzapine- and risperidone-treated patients $\left(p_{\text {interac- }}\right.$ tion $=0.001)(\mathbf{b}) ; M D R 13435 \mathrm{CT}$ polymorphism in olanzapinetreated patients $\left(p_{\text {interaction }}=0.03\right)(\mathbf{c})$.

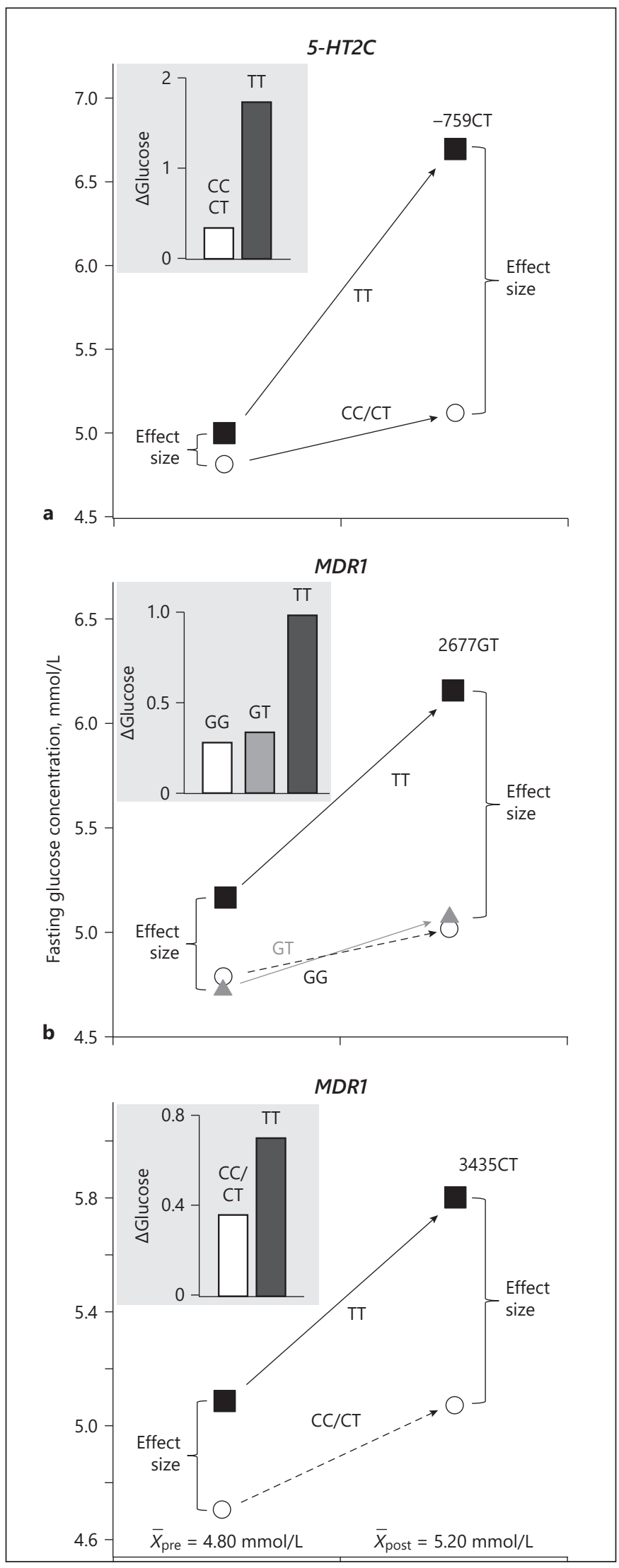




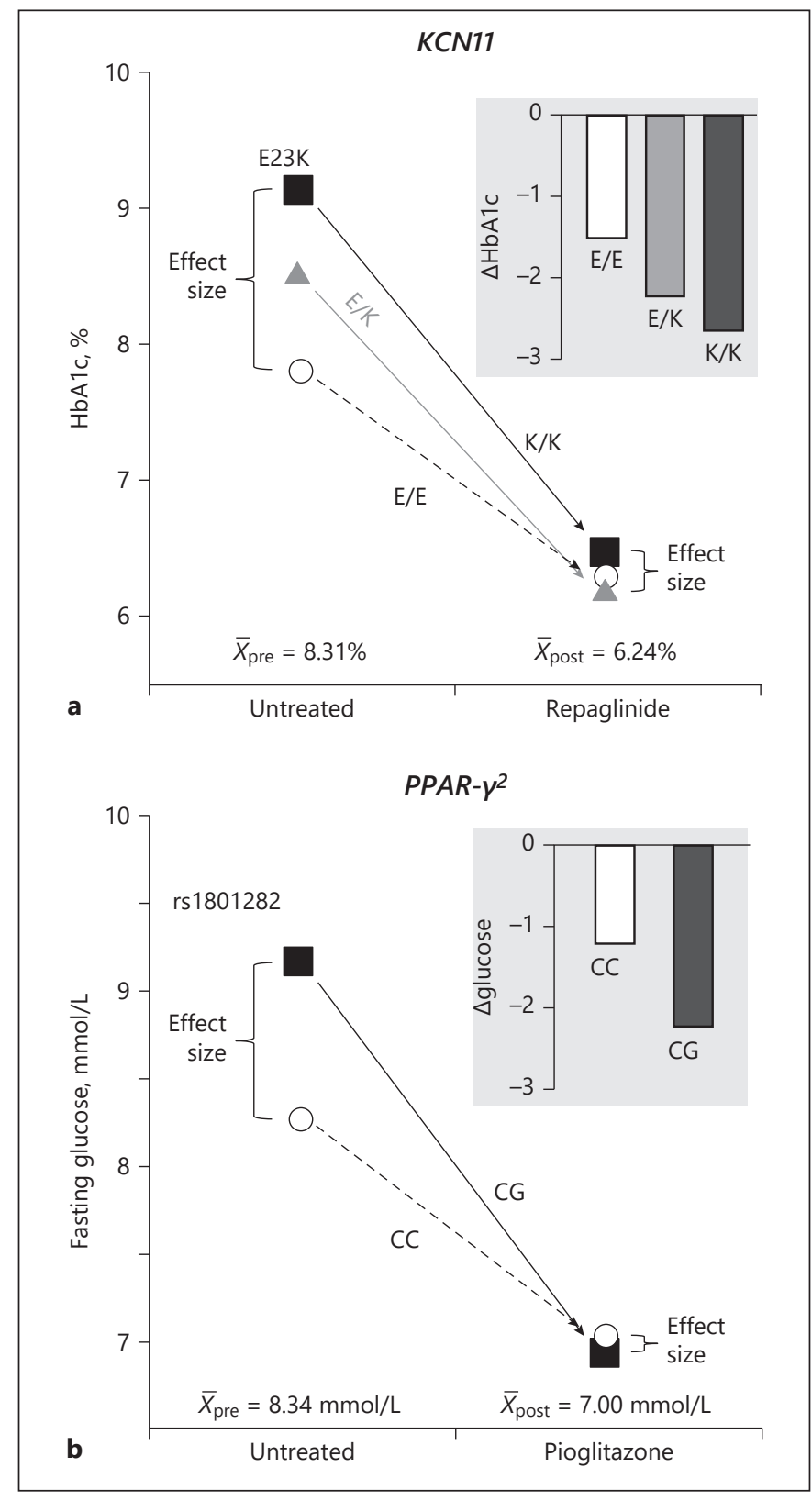

Fig. 6. a Histogram representing the precision medicine interpretation of He et al.s [40] report showing significantly greater $\mathrm{HbA1c}$ reductions in $54 \mathrm{E} / \mathrm{K}$ and $11 \mathrm{~K} / \mathrm{K}$ patients versus $35 \mathrm{E} / \mathrm{E}$ patients for the KCNJ11 E23K variant after a 24-week repaglinide treatment $\left(p_{\text {interaction }}=0.02\right)$. Line graphs present an quantile-dependent expressivity interpretation where a smaller post-treatment genetic effect size occurs when the average HbAlc was low versus a larger pretreatment genetic effect size when the average glucose concentration was high, requiring nonparallel glucose decreases by genotype. $\mathbf{b}$ Histogram representing the precision medicine interpretation of Pei et al.s [41] report showing significantly greater fasting glucose reductions in $7 \mathrm{CG}$ heterozygotes than $60 \mathrm{CC}$ homozygotes of the PPAR- $\gamma 2$ rs1801282 polymorphism after a 3-month pioglitazone treatment $\left(p_{\text {interaction }}=0.02\right)$. Line graphs present their interpretations from a quantile-dependent expressivity perspective. concentrations (average \pm SE: $12.03 \pm 0.47$ vs. $10.10 \pm 0.37$ $\mathrm{mIU} / \mathrm{L})$. Similarly, pretreatment fasting insulin concentrations were related to the number of FTO rs9939609 A-alleles $(p=0.04)$, whereas on-treatment concentrations were not $(p=0.45)$.

Sulfonylureas (tolbutamide, glibenclamide, glyburide, gliclazide, and glimepiride) increase insulin secretion by closing the pancreatic $\beta$-cell potassium channels [44]. Feng et al.'s [45] data showed that gliclazide produced greater reductions in fasting glucose in Ala/Ala homozygotes than Ser-allele carriers of the ABCC8 Ser1369Ala polymorphism ( -3.90 vs. $-3.32 \mathrm{mmol} / \mathrm{L})$. Consistent with quantile-dependent expressivity, there was a greater difference between genotypes before treatment $(0.46 \pm$ $0.24 \mathrm{mmol} / \mathrm{L}$ ) when overall average glucose concentrations were high $(11.13 \pm 0.09 \mathrm{mmol} / \mathrm{L})$ than after treatment $(-0.12 \pm 0.18 \mathrm{mmol} / \mathrm{L})$ when overall concentrations were lower $(7.69 \pm 0.07 \mathrm{mmol} / \mathrm{L})$.

\section{Gene-Environment Interactions}

An important consequence of quantile-dependent expressivity is that environmental conditions that distinguish high-valued phenotypes from low-valued phenotypes will show different genetic effects. Such differences have traditionally been interpreted as biological interactions between gene and environment when a simpler interpretation based on quantile-dependent expressivity might suffice.

\section{Low Birth Weight}

The "fetal origins" theory hypothesizes that diabetes originates through an adverse developmental environment as indicated by low birth weight [46]. It is an example where adversity during gestation produces metabolic and morphological changes that increase disease risk in later life. "Developmental plasticity" ensues, where a genotype gives rise to different structures and functions in response to developmental conditions. For example, infants born small for their gestational age (SGA) have decreased adult insulin sensitivity relative to those whose birth weights were appropriate for their gestational age (AGA) [47].

Jaquet et al. [48] reported that 3 polymorphisms of key adipose tissue molecules modulated insulin resistance in reduced fetal growth: the tumor necrosis factor- $\alpha(T N F-\alpha)$ G-308A polymorphism, $\beta 3$ adrenoreceptor (ADRB3) $\mathrm{G}+250 \mathrm{C}$ polymorphism, and peroxisome proliferatoractivated receptor- $\gamma 2(P P A R-\gamma 2)$ Pro12Ala polymorphism. Specifically, the histograms in Figure 7 show that the SGA minus AGA difference in fasting insulin concentrations 
was greater in A-allele carriers than GG homozygotes of the TNF- $\alpha$ G-308A polymorphism (Fig. 7a: $12.0 \pm 4.9$ vs. $\left.3.0 \pm 2.6 \mathrm{pmol} / \mathrm{L}, p_{\text {interaction }}=0.03\right)$, greater in $\mathrm{C}$-carriers than GG homozygotes of the ADRB3 $\mathrm{G}+250 \mathrm{C}$ polymorphism (Fig. $7 \mathrm{~b}: 21 \pm 11.8$ vs. $3.6 \pm 2.2 \mathrm{pmol} / \mathrm{L}$, $p_{\text {interaction }}=$ 0.01 ), and greater in Ala-carriers versus Pro/Pro homozygotes of the PPAR- $\gamma 2$ Pro12Ala polymorphism (Fig. $7 \mathrm{c}: 10.2 \pm 4.6$ vs. $3.6 \pm 2.2 \mathrm{pmol} / \mathrm{L}$, $p_{\text {interaction }}=0.03$ ). Alternatively, the line graphs in Figure 7 suggest the interactions could be attributed to quantile-dependent expressivity and the larger genetic effect sizes at the higher average insulin concentrations of SGA births vis-à-vis the lower average insulin concentrations of the AGA births $\left(35.4 \pm 2.20\right.$ vs. $29.8 \pm 0.86 \mathrm{pmol} / \mathrm{L}, p_{\text {difference }}=$ $0.03)$. Corresponding analyses suggesting quantile-dependent expressivity for fasting insulin/glucose ratio and insulin AUC following a 75-g OGTT are presented in online supplementary Figure 1 (for all online suppl. material, see www.karger.com/doi/10.1159/000519382).

Eriksson et al. [49] reported that birth weight significantly affected fasting insulin concentrations $(p=0.003)$ and HOMA-IR $(p=0.002)$ in PPAR- $\gamma 2$ Pro12Pro homozygotes, but not carriers of the Ala-allele $(p=0.31$ and $p$ $=0.47$, respectively), leading to a significant gene-birth weight interaction in the elderly ( $p_{\text {interaction }}=0.03$ and 0.05 , respectively). However, their data showed that the fasting insulin difference between genotypes increased as birth weight got smaller, that is, no difference for $>3,500$ $\mathrm{g}$ births, an $11 \mathrm{pmol} / \mathrm{L}$ difference for 3,500 $\mathrm{g}$ births, and a $24 \mathrm{pmol} / \mathrm{L}$ difference for 3,000 $\mathrm{g}$ births. Mean fasting insulin concentrations also increased with smaller births $(65,67.8$, and $74.5 \mathrm{pmol} / \mathrm{L}$, respectively). From the perspective of quantile-dependent expressivity, low birth weight increased insulin concentrations, which in turn

Fig. 7. Jaquet et al.'s [48] report on fasting insulin concentrations in young adults born SGA and born AGA by: A-allele carriers $\left(N_{\mathrm{SGA}}=46, N_{\mathrm{AGA}}=61\right)$ and GG homozygotes $\left(N_{\mathrm{SGA}}=125, N_{\mathrm{AGA}}\right.$ $=172)$ of the tumor necrosis factor- $\alpha(T N F-\alpha)$ G-308A polymorphism $\left(p_{\text {interaction }}=0.03\right)(\mathbf{a})$; C-carriers $\left(N_{\mathrm{SGA}}=19, N_{\mathrm{AGA}}=26\right)$ and GG homozygotes $\left(N_{\mathrm{SGA}}=152, N_{\mathrm{AGA}}=207\right)$ of the $\beta 3$ adrenoreceptor $(A D R B 3) \mathrm{G}+250 \mathrm{C}$ polymorphism $\left(p_{\text {interaction }}=0.01\right)(\mathbf{b})$; and Ala-carriers $\left(N_{\mathrm{SGA}}=38, N_{\mathrm{AGA}}=54\right)$ versus Pro/Pro homozygotes $\left(N_{\mathrm{SGA}}=133, N_{\mathrm{AGA}}=179\right)$ of the PPAR- $\gamma 2$ Pro12Ala polymorphism $\left(p_{\text {interaction }}=0.03\right)(\mathbf{c})$. The histograms present the precision medicine interpretation of genotypes affecting the fasting insulin difference between SGA and AGA births, the line graphs present the quantile-dependent expressivity interpretation of a larger genetic effect size at the higher average fasting insulin concentrations. $P P A R-\gamma 2$, peroxisome proliferator-activated receptor- $\gamma 2$; AGA, appropriate for their gestational age; SGA, small for their gestational age.

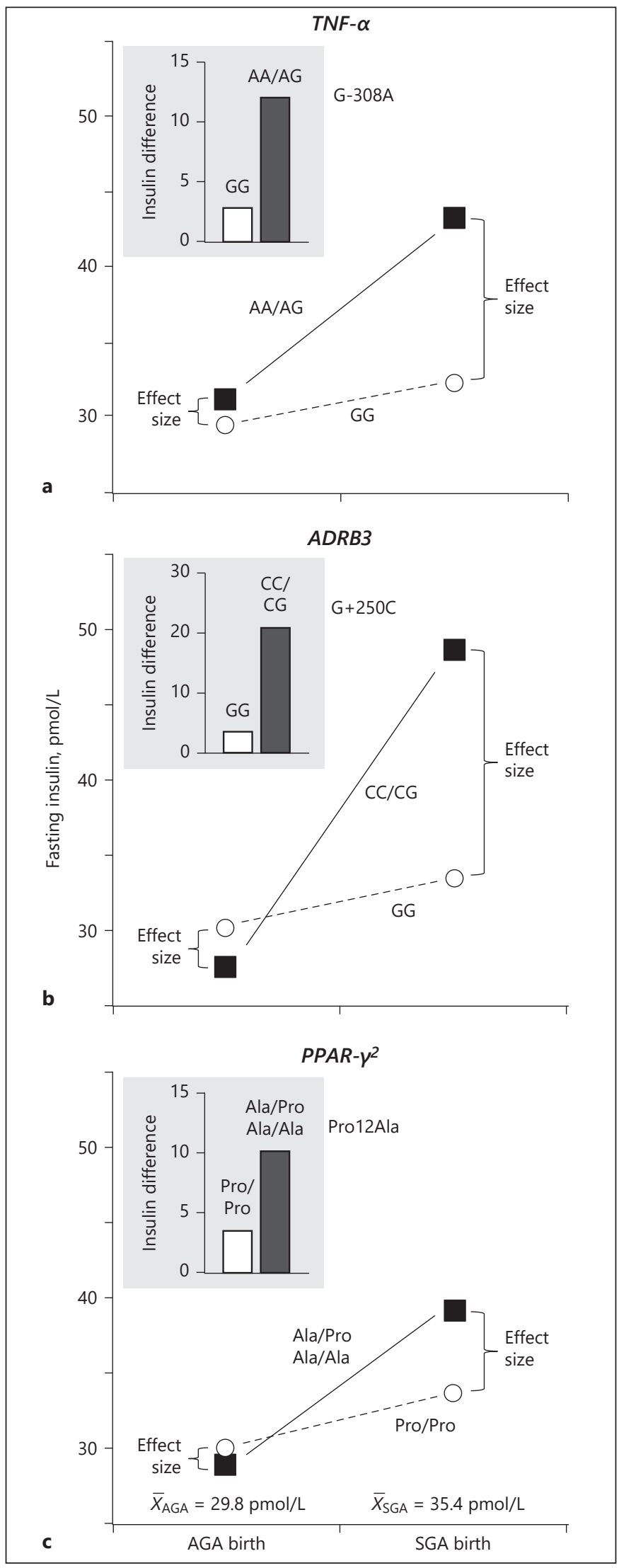


increased the genetic effect size. The authors also reported that $P P A R-\gamma 2$ genotype differences in HOMA-IR increased with smaller birth weight $(1.3,2.9$, and 7 , respectively), as did mean HOMA-IR levels (16.1, 17.0, and 18.8 , respectively), consistent with quantile-dependent expressivity (i.e., higher mean producing a larger genetic effect).

In their study of elderly adults, Kajantie et al. [50] reported that the I allele of the insertion/deletion polymorphism in the angiotensin-converting enzyme gene $(A C E)$ was significantly associated with a greater insulin response at $30 \mathrm{~min}(p=0.0004)$, and greater insulin AUC $(p=0.008)$ during a OGTT, only in the lowest tertile of birth weight $\left(p_{\text {interaction }}=0.003\right.$ and $p_{\text {interaction }}=0.05$, respectively). However, the lowest birth weight tertile had the highest average insulin at $30 \mathrm{~min}$ (1st: 520, 2nd: 477, $3 \mathrm{rd}: 425 \mathrm{pmol} / \mathrm{L}$ ) and the highest insulin AUC (1st: 415, 2nd: 383, 3rd: $343 \mathrm{pmol} / \mathrm{L}$ ), consistent with quantiledependent expressivity. Kajantie et al.'s [50] results were consistent with an earlier study by Cambien et al. [51], which showed that the association of the I-allele to the OGTT insulin response was confined to young adults born SGA.

To summarize, quantile-dependent expressivity suggests that altered morphological development from an unfavorable fetal environment contributes to insulin resistance and $\beta$-cell dysfunction in adulthood, and it is the reduced glucose tolerance during adulthood that affects the phenotypic expression of these genetic variants. These effects may be in addition to genetic effects that contribute to both low birth weight and glucose intolerance.

\section{Adiposity}

Adiposity is the strongest modifiable risk factor for T2DM [52]. Increased secretion of non-esterified fatty acids and other products (e.g., glycerol, leptin, pro-inflammatory cytokines) by the adipose tissue of obese individuals may lead to the development of insulin resistance [53]. Body fat distribution also plays a role in determining

Fig. 8. Histograms representing the traditional interpretation of genotypes modifying the effect of adiposity versus line graphs representing the quantile-dependent expressivity interpretation of a larger genetic effect size at the higher average phenotype value for: Ukkola et al.s [55] report on the significantly greater increase in fasting insulin from 100-day overfeeding in $10 \mathrm{GlnGln}$ homozygotes and 14 carriers of the Arg-allele for the leptin receptor Gln223Arg polymorphism (a); the corresponding results for OGTT AUC insulin concentrations (estimated by integration of their Fig. 2 [55]) (b); de Luis et al.'s [56] report of significantly different $(p<0.05)$ HOMA-IR insulin resistance, tending to be greater in subjects whose fat is centrally located in abdominal and chest areas and less in those whose fat is distributed peripherally. Consistent with our finding of concordance between genetic effect size and mean concentrations, Wang et al. [54] estimated that the heritability for the quantitative insulin-sensitivity check index (QUICKI) was 31 percentage points higher $(p<0.001)$ among twins concordant for overweight $\left(h^{2}=0.81 ; 95 \%\right.$ CI $\left.0.65-0.90\right)$ relative to twins concordant for normal weight $\left(h^{2}=0.50\right.$; 95\% CI 0.37-0.60).

Ukkola et al. [55] reported that overfeeding 12 identical twins $4.2 \mathrm{MJ} /$ day for 100 days significantly increased body weight $(8.1 \mathrm{~kg})$, fasting insulin concentrations (22 $\mathrm{pmol} / \mathrm{L}$ ), and OGTT AUC insulin concentrations (16.1 pmol L $\left.{ }^{-1} \mathrm{~min}^{-1} 10^{-3}\right)$. Compared to the 14 carriers of the Arg-allele of the leptin receptor (LEPR) Gln223Arg polymorphism, the $10 \mathrm{GlnGln}$ homozygotes had significantly greater increases in fasting insulin $(44.8 \pm 2.5$ vs. $5.5 \pm$ 0.89 , Fig. 8 a histogram), OGTT AUC insulin concentrations ( 30.3 vs. 6.7 pmol L-1 $\mathrm{min}^{-1} 10^{-3}, p=0.04$, Fig. $8 \mathrm{~b}$ ), and fat body mass $(6.1 \pm 0.2$ vs. $4.8 \pm 0.1 \mathrm{~kg}$, not displayed). Alternatively, quantile-dependent expressivity would ascribe the genotype differences in $\Delta$ fasting insulin and $\triangle \mathrm{AUC}$ insulin to the larger genetic effect size after weight gain $\left(46.8 \pm 2.35 \mathrm{pmol} / \mathrm{L}\right.$ and $54.14 \mathrm{pmol} \mathrm{L}^{-1} \mathrm{~min}^{-1}$ $10^{-3}$, respectively) when mean concentrations were higher vis-à-vis the smaller genetic effect size $(7.5 \pm 1.43$ $\mathrm{pmol} / \mathrm{L}$ and $30.6 \mathrm{pmol} \mathrm{L} \mathrm{min}^{-1} 10^{-3}$, respectively) before weight gain when mean concentrations were lower (Fig. 8a, b line graphs).

Another intervention study, reported by de Luis et al. [56], showed that GG homozygotes of the resistin (RETN) rs1862513 polymorphism attained significantly greater decreases in fasting glucose concentrations than carriers of the C-allele $(-0.400 \pm 0.026$ vs. $-0.044 \pm 0.001 \mathrm{mmol} / \mathrm{L}$, $p=0.01$ ) during a 3-month low-fat hypocaloric diet. The significant baseline difference between genotypes $(0.261$ $\pm 0.101 \mathrm{mmol} / \mathrm{L})$ became nonsignificant $(-0.094 \pm 0.112$ reductions in 56 GG homozygotes versus 77 carriers of the C-allele of the resistin $(R E T N)$ rs 1862513 polymorphism following a 3-month low-fat hypocaloric diet (c); van Dam et al.s [57] report of parental history of diabetes modifying the effect of abdominal obesity on fasting glucose concentrations in men $\left(p_{\text {interaction }}=0.003\right)(\mathbf{d})$; corresponding analysis in women $\left(p_{\text {interaction }}=0.002\right)$ [57] (e); Elosua et al.s. [59] report on the significant interaction $(p=0.008)$ between APOE genotypes $(12.9 \% \mathrm{E} 2+, 66.9 \% \mathrm{E} 33,20.3 \% \mathrm{E} 4+)$ and male obesity status on fasting glucose concentrations (f). HOMA-IR, homeostatic model assessment of insulin resistance.

(For figure see next page.) 


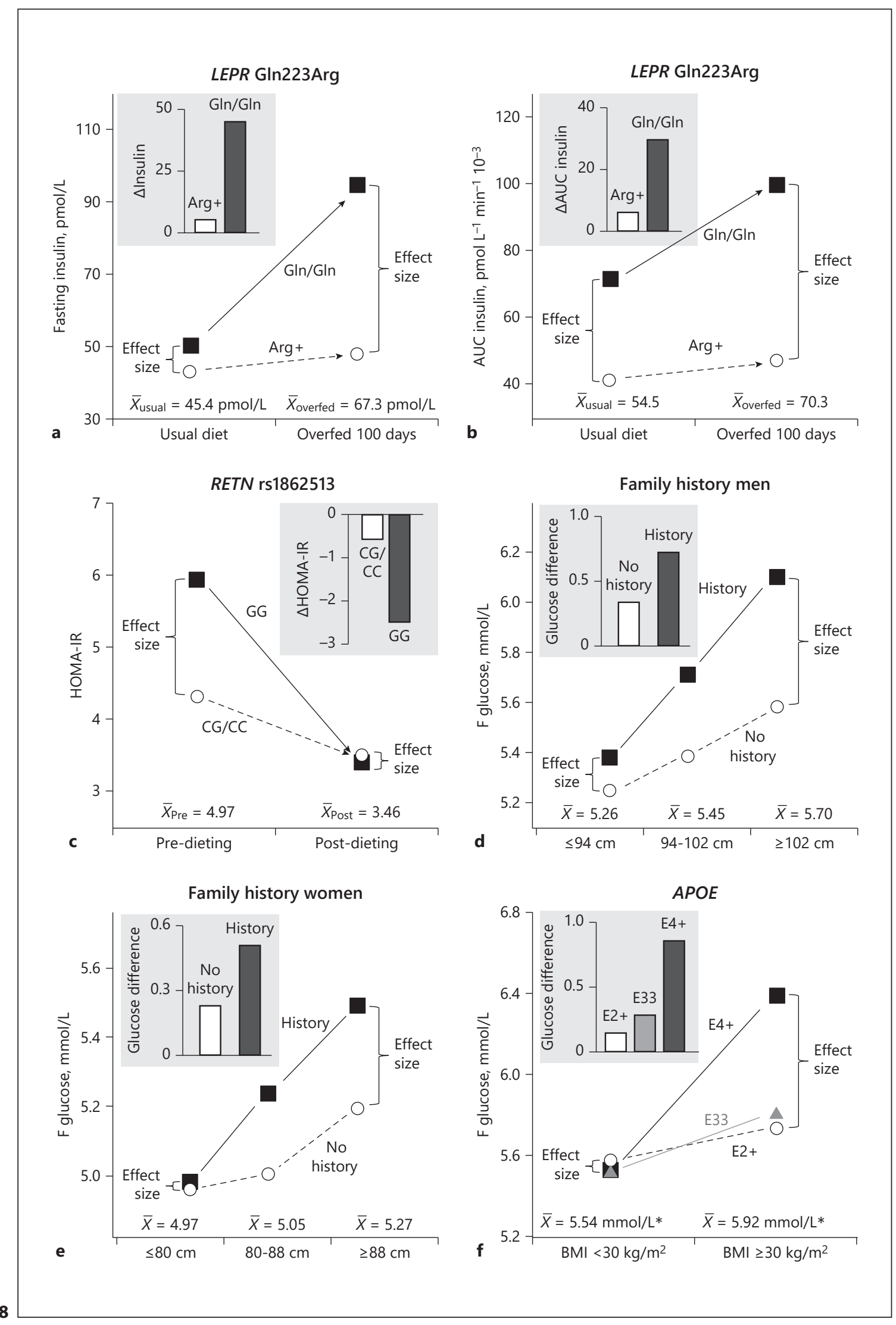


$\mathrm{mmol} / \mathrm{L})$ as mean glucose concentrations diminished from $5.527 \pm 0.051$ to $5.333 \pm 0.056 \mathrm{mmol} / \mathrm{L}$. Similarly, significant differences between GG homozygotes and Callele carriers for $\Delta$ fasting insulin $(-5.6 \pm 0.33$ vs. $-2.9 \pm$ $0.14 \mathrm{mUI} / \mathrm{L}, p=0.03)$ and $\Delta$ HOMA-IR $(-2.5 \pm 0.15$ vs. $-0.6 \pm 0.16, p=0.02$, Fig. $8 \mathrm{c}$ histogram) may be attributable to the larger pre-diet than post-diet genotype differences in fasting insulin $(1.8 \pm 1.42$ vs. $-0.8 \pm 1.30 \mathrm{mUI} / \mathrm{L})$ and HOMA-IR $(1.6 \pm 0.39$ vs. $-0.1 \pm 0.34$ Fig. $8 \mathrm{c}$ line graph) in accordance with quantile-dependent expressivity and the larger pre-diet than post-diet average fasting insulin (18.26 \pm 0.73 vs. $14.16 \pm 0.66 \mathrm{mUI} / \mathrm{L})$ and HOMAIR values $(4.97 \pm 0.20$ vs. $3.46 \pm 0.18)$.

Cross-sectionally, van Dam et al. [57] reported that the effect of waist circumference on fasting glucose concentrations was twice as great in subjects with a family history of diabetes than those without (men: $\beta=0.31 \pm$ 0.09 vs. $0.16 \pm 0.02$, $p_{\text {interaction }}=0.003$; women $(\beta=0.24 \pm$ 0.05 vs. $\left.0.11 \pm 0.02, p_{\text {interaction }}=0.002\right)$. The histograms of Figure $8 \mathrm{~d}$ and e display the glucose difference between the lowest and highest waist circumference by family history, while the line graphs show a strong correspondence between the effect of family history and average glucose concentrations by waist circumference, consistent with the inherited effects being quantile-dependent.

Kim et al. [58] reported that a 20-SNP obesity GRS showed a significantly greater effect on fasting insulin concentration for men with waist circumferences $\geq 90 \mathrm{~cm}$ and women with waist circumferences $\geq 85 \mathrm{~cm}(\beta=0.037$ $\pm 0.03)$ than in less centrally obese subjects $(\beta=0.003 \pm$ $\left.0.016, p_{\text {interaction }}<0.001\right)$. The corresponding effect sizes for HOMA-IR were $\beta=0.044 \pm 0.027$ in the wider-waisted participants versus $\beta=0.001 \pm 0.015$ in the narrowerwaisted participants $\left(p_{\text {interaction }}<0.001\right)$. These interactions are consistent with quantile-dependent expressivity presuming that average fasting insulin and HOMA-IR were higher in the central obese participants (unreported in the paper).

Fig. 9. Histograms representing the traditional interpretation of genotypes modifying the effect of adiposity versus line graphs representing the quantile-dependent expressivity interpretation of a larger genetic effect size at the higher average phenotype value for: Elosua et al.s. [59] report on the significant interaction $(p=0.003)$ between APOE genotypes (12.9\% E2+, 66.9\% E33, $20.3 \% \mathrm{E} 4+$ ) and male obesity status on fasting insulin concentrations (a); Uusitupa et al. [60] report on fasting plasma insulin concentrations in 6 normal and 5 centrally obese female carriers of the APOE E2-allele, 50 normal and 42 centrally obese women having the E33 isoform, and 15 normal and 23 centrally obese female carriers of the E4-allele (estimated from their Fig. 1) (b);
Three cross-sectional studies report gene-weight interactions involving $A P O E$. Elosua et al. [59] reported significant interactions between $A P O E$ genotype and obesity on fasting insulin and glucose concentrations in men ( $p_{\text {interaction }}=0.003$ and 0.008 , respectively) but not women. The glucose difference between obese and nonobese men was significant in E4-carriers $(p<0.001)$ but not E33 homozygotes $(p=0.12)$ or E2-carriers $(p=0.99$, Fig. $8 \mathrm{f}$ histogram). The insulin difference was significant in E4-carriers $(p<0.001), \mathrm{E} 33(p<0.001)$ and E2-carriers ( $p=0.003$, Fig. 9a histogram). The accompanying line graphs show that the cross-sectional genetic effect size was greater in obese than lean men for both variables, consistent with quantile-dependent expressivity. The nonsignificant interaction in women could relate in part to their lower average glucose $(5.29 \pm 0.02$ vs. $5.63 \pm 0.04$ $\mathrm{mmol} / \mathrm{L}$ ) and insulin concentrations vis-à-vis men $(28.5 \pm 0.27$ vs. $31.8 \pm 0.36 \mathrm{pmol} / \mathrm{L})$.

Uusitupa et al. [60] reported that $A P O E$ isoforms significantly modified the effects of central obesity on fasting insulin concentrations ( $p_{\text {interaction }}=0.05$, Fig. $9 \mathrm{~b}$ ) and the insulin to glucose ratio ( $p_{\text {interaction }}=0.01$, not displayed) in overweight women. Alternatively, compared to those with normal waists, the centrally obese women had a higher average insulin to glucose ratio (mean \pm SE: $19.18 \pm 0.89$ vs. $14.23 \pm 0.59)$ and higher average fasting insulin concentrations (108.0 vs. 75.2 pmol/L, Fig. 9b line graph). Correspondingly the centrally obese women also had larger genetic effect size for both the ratio $(\mathrm{E} 4 \pm \mathrm{E} 33$ difference: $5.20 \pm 2.17$ vs. $-1.7 \pm 1.21, p=$ $0.005)$ and fasting plasma insulin concentrations (23.6 vs. $-7.4 \mathrm{pmol} / \mathrm{L}$ ).

The 3rd study by Marques-Vidal et al. [61] reported a significant BMI-APOE interaction affecting fasting insulin concentrations $\left(p_{\text {interaction }}=0.01\right)$, which they interpreted as BMI's stronger affect on insulin in E4-carriers than in E33 or E2-carriers (Fig. 9c). Quantile-dependent expressivity's prediction of larger genetic effect sizes with

Marques-Vidal et al. [61] report of fasting insulin concentrations in $30 \mathrm{APOE}$ E2-carriers, $185 \mathrm{E} 33$, and 54-carriers in 107 normal weight, 128 overweight, and 31 obese men (histogram displays the genotype-specific differences between normal weight and overweight men) (c); Jung et al.s [64] report of a significant interaction between the GCKR rs780094 polymorphism and waist circumference on fasting glucose concentrations $\left(p_{\text {interaction }}=0.02\right)(\mathbf{d})$; Baroni et al.'s [66] report of a significant interaction $(p<0.0001)$ between obesity and the G972R mutation of the insulin receptor substrate-1 (IRS-1) for fasting insulin concentrations (e); the corresponding analyses for HOMA-IR [66] (f). HOMA-IR, homeostatic model assessment of insulin resistance.

(For figure see next page.)

Quantile-Specific Inheritance of Glycemia
Lifestyle Genomics 2022;15:10-34 DOI: $10.1159 / 000519382$ 
APOE

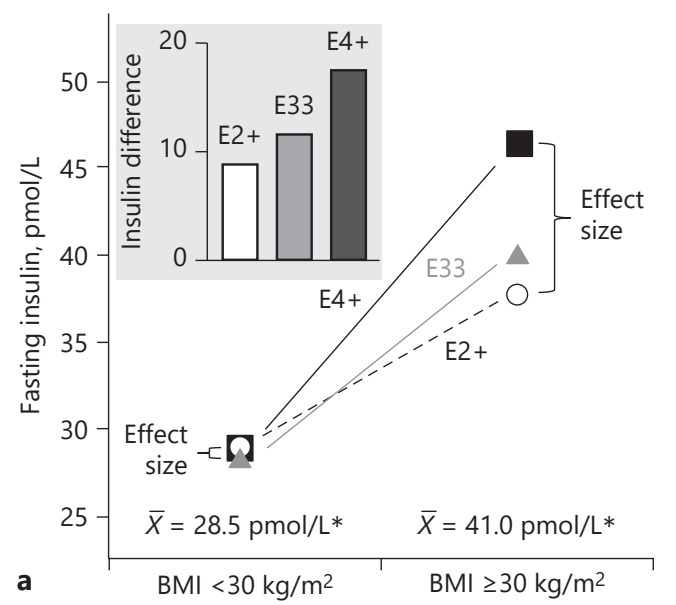

APOE

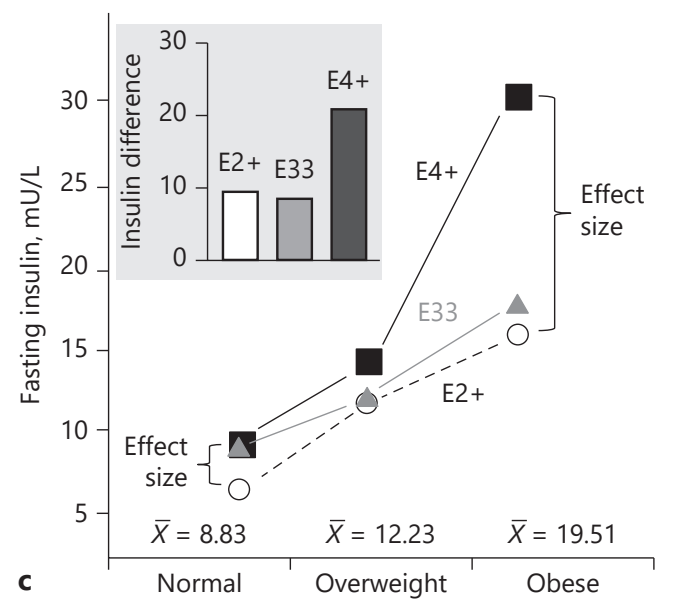

IRS-1

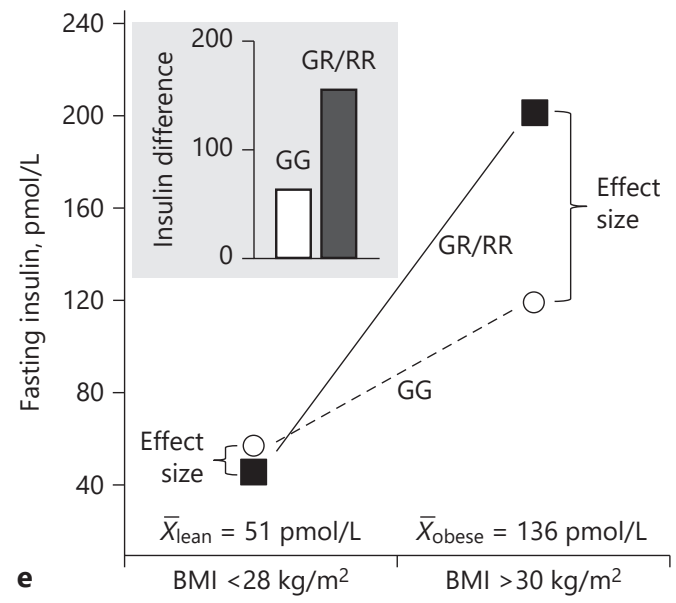

APOE

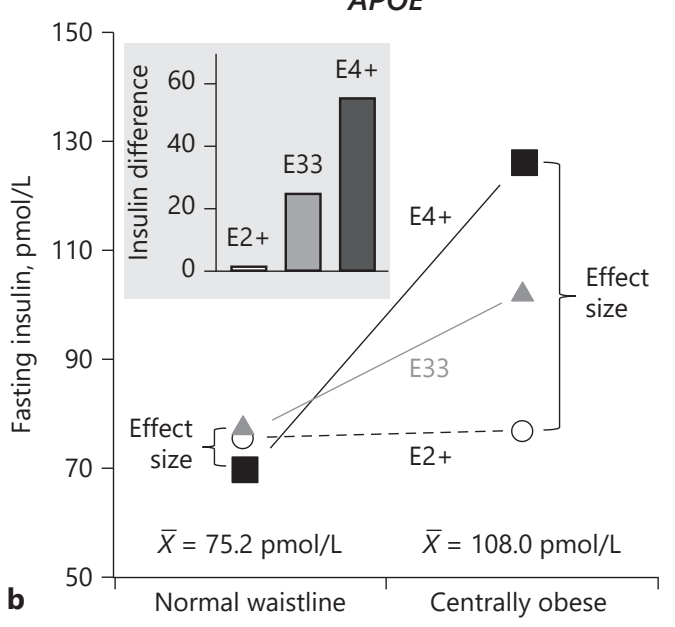

GCKR

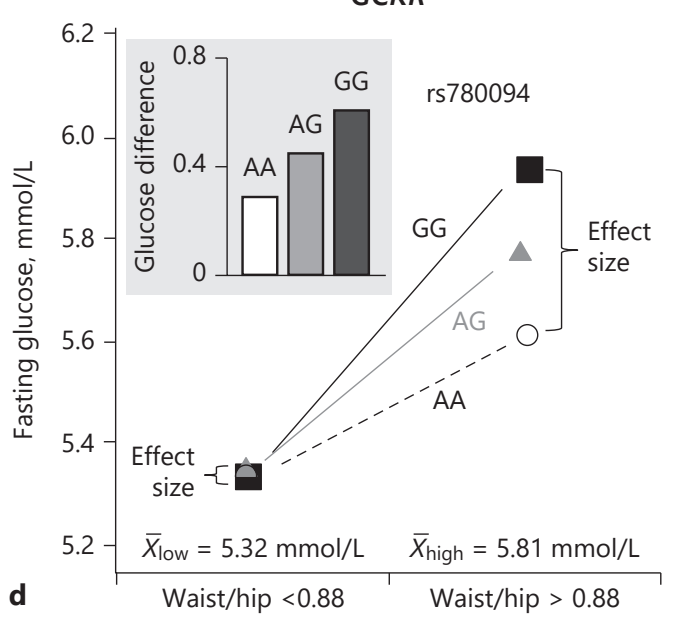

IRS-1

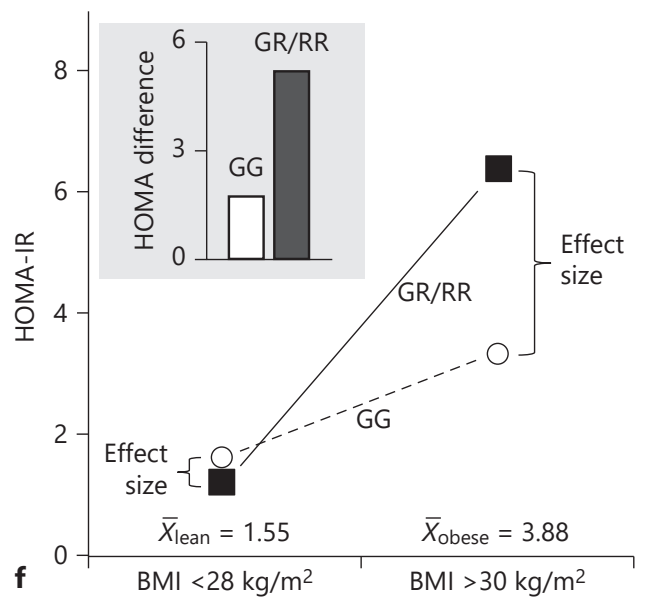

9 
increasing average fasting insulin concentrations fits their findings, that is, a small E4-E33 difference $(0.2 \pm 1.9$ $\mathrm{mU} / \mathrm{L}$ ) for the low average insulin concentration in normal weight individuals $(8.8 \pm 0.7 \mathrm{mU} / \mathrm{L})$, an intermediate E4-E33 difference $(2.5 \pm 1.5 \mathrm{mU} / \mathrm{L})$ for the intermediate average insulin concentration of overweight individuals $(12.2 \pm 0.7 \mathrm{mU} / \mathrm{L})$, and a larger difference $(12.5 \pm 3.4$ $\mathrm{mU} / \mathrm{L}$ ) for the higher average insulin concentrations in obese individuals $(19.51 \pm 1.23 \mathrm{mU} / \mathrm{L})$.

Rs290487 and rs7903146 are polymorphisms within the transcription factor 7-like 2 (TCF7L2) gene that are associated with T2DM risk [62]. Li et al. [63] reported that increasing BMI and waist circumference levels were both associated with higher average glucose concentrations as well as increasing glucose difference between CC homozygotes and T carriers of the TCF7L2 rs7903146 polymorphism $(p<0.001)$ in fasting T2DM Chinese. Increasing $\mathrm{BMI}$ and waist circumference also increased the glucose difference between T-allele carriers and CC homozygotes of the TCF7L2 rs290487 polymorphism when fasting $(p<0.001)$.

Jung et al.'s [64] report of a significant interaction between the GCKR rs780094 polymorphism and waist/hip ratio on fasting glucose concentrations may also be attributable to the larger genetic effect size associated with the higher average glucose concentrations in women with higher versus lower average ratios $\left(p_{\text {interaction }}=0.02\right.$, Fig. 9d).

Herbert et al. [65] reported that BMI significantly modified the association between the -174 interleukin (IL)-6 gene promoter polymorphism and 3 phenotypic traits in men: HOMA-IR ( $p_{\text {interaction }}=0.0001$ ), fasting insulin concentrations ( $\left.p_{\text {interaction }}=0.004\right)$, and fasting glucose concentrations ( $\left.p_{\text {interaction }}=0.02\right)$. As expected, higher BMI was associated with significantly higher HOMA-IR, fasting insulin, and fasting glucose (all $p<0.0001$ ). Consistent with quantile-dependent expressivity, their figures 1 and 2 showed progressively greater differences between genotypes as the BMI increased from 20 to $40 \mathrm{~kg} / \mathrm{m}^{2}$. The lack of a significant interaction in women may relate to their significantly lower HOMA-IR (women vs. men: $6.80 \pm 0.12$ vs. $8.03 \pm 0.15$ ), fasting insulin $(4.7 \pm 0.06 \mathrm{vs} .5 .3 \pm 0.08 \mathrm{pmol} / \mathrm{L})$, and fasting glucose $(5.3 \pm 0.03$ vs. $5.6 \pm 0.04 \mathrm{mmol} / \mathrm{L})$.

Baroni et al. [66] reported significantly worsening insulin sensitivity due to the significant interaction between obesity and the G972R mutation of the insulin receptor substrate- 1 gene (IRS-1, $p<0.0001)$. Specifically, the histograms of Figure 9e and $\mathrm{f}$ show that the difference between obese and lean Italians was greater for carriers of the R-allele than GG homozygotes for both fasting insulin concentrations and HOMA-IR. However, the genetic effect size between R-carriers and GG homozygotes was also greater in the obese than lean subjects for fasting insulin (difference \pm SE: $81.70 \pm 27.93$ vs. $-10.8 \pm 4.48$ pmol/L, $p=0.001)$ and HOMA-IR (3.04 \pm 0.82 vs. -0.40 $\pm 0.57, p=0.0006$ ), consistent with quantile-dependent expressivity and the higher averages concentrations in obese than lean subjects for insulin (average \pm SE: 135.5 \pm 10.0 vs. $50.6 \pm 2.8 \mathrm{pmol} / \mathrm{L}, p<0.0001)$ and HOMA-IR $(3.88 \pm 0.20$ vs. $1.55 \pm 0.1, p<0.0001)$.

Jaquet et al. [48] showed that the effect of adult BMI on the insulin-to-glucose ratio was greater in $A D R B 3$ $\mathrm{G}+250 \mathrm{C}$ GG homozygotes than C-allele carriers ( $p_{\text {interac- }}$ tion $=0.009)$ and greater in the PPAR- $\gamma 2$ Pro12Ala Alaallele carriers than Pro/Pro homozygotes $\left(p_{\text {interaction }}=\right.$ 0.005), from which they deduced that adult BMI potentiated the effects of these polymorphisms on insulin resistance. Their Figure 2 showed that increasing BMI was associated with: (1) mean increases in the insulin-toglucose ratio, and (2) progressively greater differences in the ratio between genotypes for both polymorphisms, consistent with quantile-dependent expressivity.

Quantile-dependent expressivity may also contribute to BMI's potentiating effect on genes affecting fasting glycemic traits and insulin resistance in GWA studies. Manning et al. [67] reported that the effect of rs 1801282 (PPARG P12A) on log (fasting insulin) increased as BMI increased progressively from 25 (effect \pm SE: $0.041 \pm$ $0.007)$, to $30(0.049 \pm 0.009)$, to $35 \mathrm{~kg} / \mathrm{m}^{2}(0.057 \pm 0.016)$ in their meta-analysis of 19,466 subjects from 5 cohorts. In another meta-analysis of up to 96,496 subjects from 52 studies [68], they reported significantly larger genetic size for BMI $>28$ than $<28 \mathrm{~kg} / \mathrm{m}^{2}$ for rs7607980 near the COBLL1-GRB14 IRS1 locus ( $\beta \pm$ SE: $0.041 \pm 0.006$ vs. 0.018 $\left.\pm 0.004, p_{\text {interaction }}=0.02\right)$, MFHAS1 rs408459 $(0.017 \pm$ 0.005 vs. $0.007 \pm 0.003$, $\left.p_{\text {interaction }}=0.03\right)$, and KIAA0280 rs7 $102738\left(-0.040 \pm 0.015\right.$ vs. $-0.005 \pm 0.010, p_{\text {interaction }}=$ $0.05)$ for $\log$ fasting insulin, and GCKR rs780094 ( -0.047 \pm 0.006 vs. $-0.026 \pm 0.003$, $\left.p_{\text {interaction }}=0.003\right)$, and IGF2BP2 rs $1470579(-0.028 \pm 0.006$ vs. $-0.008 \pm 0.004$, $\left.p_{\text {interaction }}=0.02\right)$ for fasting glucose concentrations. Stolerman et al. [69] reported that the effect of the ectonucleotide pyrophosphatase phosphodiesterase 1 (ENPP1) K121Q polymorphism on fasting glucose concentrations and HOMA-IR were strengthened by higher BMI ( $p_{\text {interaction }}=0.008$ and $p_{\text {interaction }}=0.01$, respectively). Presumably fasting insulin, fasting glucose, and HOMAIR increased with increasing BMI in these populations (not actually reported). 


\section{Physical Activity}

Physical activity increases insulin sensitivity [70]. Waterworth et al. [71] report that weekly exercise interacted significantly with a surrogate marker of the insulin gene (INS) variable number tandem repeat (VNTR) on AUC insulin concentrations $\left(p_{\text {interaction }}=0.03\right)$, such that there were greater differences between class III carriers (141209 repeats) vis-à-vis class I homozygotes (26-63 repeats) for 60-min OGTT insulin concentrations in those reporting little or no exercise than those that exercised. Equivalently, the histogram of Figure 10a shows that the effect of low physical activity on insulin AUC was greatest for III/III, intermediate for I/III, and least for I/I genotypes. Alternatively, mean AUC insulin concentrations were higher in the least active, intermediate in the intermediate active, and lowest in the most-active exercisers, and consistent with quantile-dependent expressivity, the line graph suggest the interaction could be the consequence of the larger genetic effect size at higher AUC insulin concentrations.

\section{Diet}

Insulin resistance is increased by total and saturated fat intake [72] and relatively higher saturated fat (e.g., palmitic acid) and lower polyunsaturated fat intakes (e.g., linoleic acid) [73], but the effects of dietary carbohydrates are less clear [72]. Huang et al. [74] reported that total dietary fat increased mean fasting glucose and HOMA-IR levels and accentuated the contribution of additive genetic effects on these traits in twins. Data presented by Mohan et al. [75] showed that the effect of visible fat intake on the prevalence of glucose intolerance (\%) was greater in Asian Indians with a family history of diabetes than those without (Fig. 10b histogram). However, glucose intolerance increased with visible fat intake, and consistent with quantile-dependent expressivity the effect of family history on glucose intolerance was greater in Indians above than below the median of visible fat intake (line graph).

Other reported diet-gene interactions also appear attributable to quantile-dependent expressivity due to

Fig. 10. Histograms representing the traditional interpretation of genotypes modifying the effect of physical activity or diet versus line graphs representing the quantile-dependent expressivity interpretation of a larger genetic effect size at higher average phenotype values for: Waterworth et al.s [71] report that a surrogate marker for the insulin gene (INS) VNTR modified the effect of physical activity on OGTT AUC insulin concentrations $\left(p_{\text {interaction }}=0.03\right)(\mathbf{a})$; Mohan et al.s [75] report that family history of diabetes modified the effect of visible dietary fat on glucose intolerance (b); Dziwura et al's [76] larger genetic effects coincident with higher average HOMA-IR, fasting glucose, or fasting insulin values. Data presented by Dziwura et al. [76] showed that fasting insulin and HOMA-IR differences between Gly/Arg and Gly/Gly genotypes of the IRS-1 G972R polymorphism were more pronounced at the end of a 7 -day high-salt diet than at a 7-day low-salt diet. The histograms in Figure 10c and $\mathrm{d}$ show that the fasting insulin and HOMA-IR increases from going from the low- to the high-salt diets were greater in carriers of the Arg-allele. The associated line graphs suggest that quantile-dependent expressivity would attribute some of the cross-sectional genotype differences in fasting insulin (high vs. low salt: $5.16 \pm 1.42$ vs. $3.81 \pm 1.26 \mu \mathrm{IU} / \mathrm{mL}$, respectively) and HOMA-IR $(1.50 \pm 0.28$ vs. $0.69 \pm 0.26$, respectively) to the higher overall mean values on the high-salt than low-salt diet for fasting insulin $(9.89 \pm 0.43 \mathrm{vs} .7 .54 \pm 0.36 \mu \mathrm{IU} / \mathrm{mL}$, respectively) and HOMA-IR $(1.82 \pm 0.07$ vs. $1.63 \pm 0.09)$.

Smith et al. [77] reported that the perilipin (PLIN) $11482 \mathrm{G}>\mathrm{A}$ polymorphism (rs894160) significantly modified the relationship of the saturated fat/carbohydrate intake ratio to fasting insulin concentrations $\left(p_{\text {interaction }}=\right.$ $0.025)$ and to HOMA-IR $\left(p_{\text {interaction }}=0.03\right)$ in their study of 508 US women. A higher dietary ratio was associated with a $16.67 \mathrm{pmol} / \mathrm{L}$ fasting insulin increase in T-allele carriers versus a $4.05 \mathrm{pmol} / \mathrm{L}$ increase in CC-homozygotes, and a 0.83 HOMA-IR increase in T-allele carriers versus a 0.30 increase in CC-homozygotes (Fig. 10e, f histograms). Alternatively, the genotype difference (CT/TT minus CC) was significant for fasting insulin (11.92 pmol/L, $p=0.003)$ and HOMA-IR $(0.51, p=0.004)$ when the dietary ratio was high but not when low $(-0.7 \mathrm{pmol} / \mathrm{L}$ and -0.02 , respectively, $p=0.85$ for both), suggesting that the interaction could be partially a consequence of quantile-dependent expressivity and the higher average overall fasting insulin concentration ( $87.2 \mathrm{vs.} 76.8 \mathrm{pmol} / \mathrm{L})$ and HOMA-IR (3.51 vs. 2.94) when the ratio was high versus low.

Data presented by Phillips et al. [78] showed that the fasting glucose difference below and above the median for

report that the insulin receptor substrate-1 gene (IRS-1) G972R polymorphism (rs1801278) modified the effects of low and high salt diets on fasting insulin concentrations (c); the corresponding results for HOMA-IR [76] (d); Smith et al.s [77] report that the perilipin $(P L I N) 11482 \mathrm{G}>\mathrm{A}$ polymorphism modified the effect of the dietary saturated fatty acid/carbohydrate ratio on fasting insulin concentrations (e); and the corresponding results for HOMAIR [77] (f). HOMA-IR, homeostatic model assessment of insulin resistance; VNTR, variable number tandem repeat.

(For figure see next page.)
Williams 


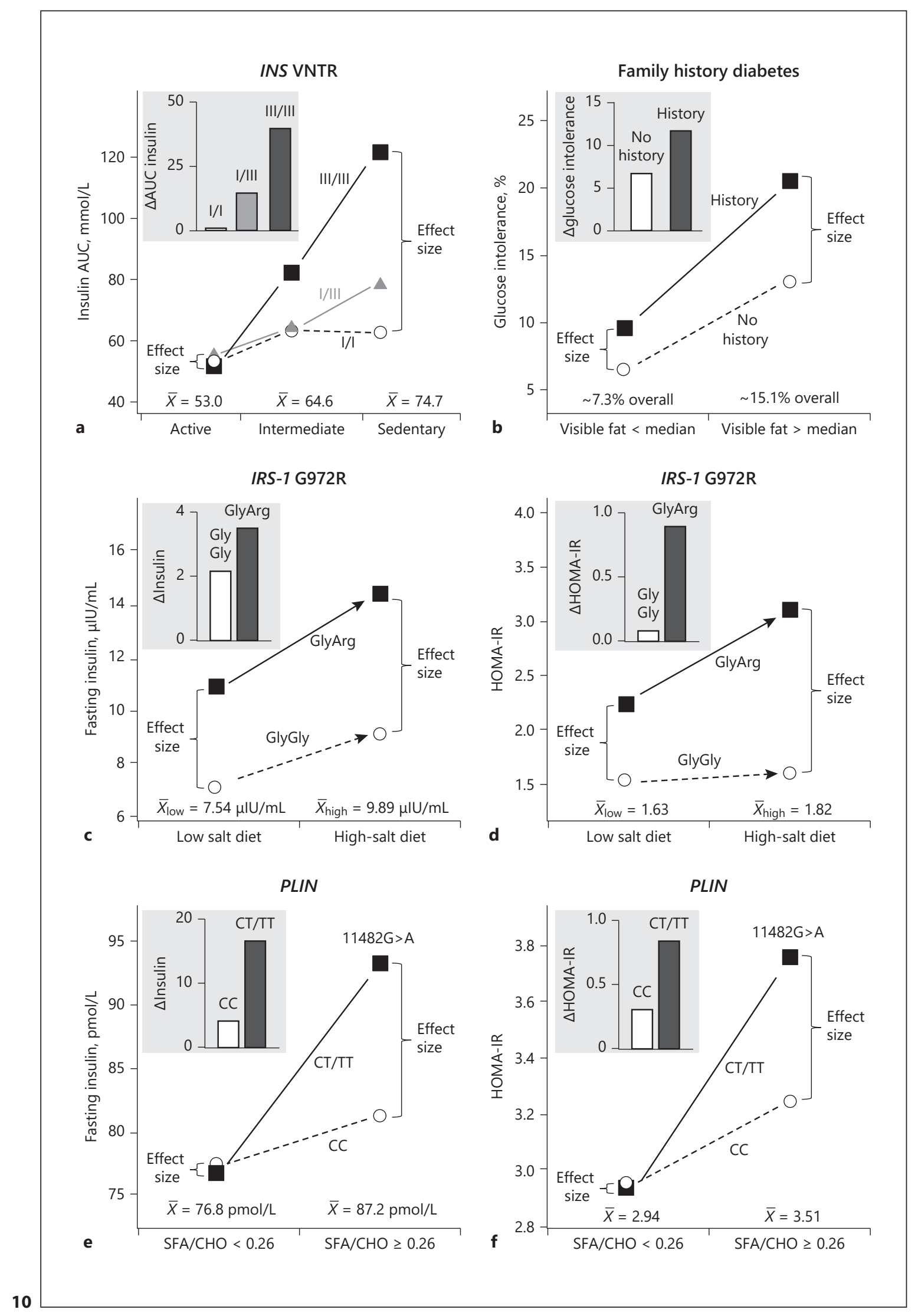


high polyunsaturated fat intake (5.5\% of energy) was significant in GG homozygotes $(p=0.01)$ but not in carriers of the A-allele of the long-chain acyl CoA synthetase (ACSL1) gene (rs9997745, Fig. 11a histogram). Average fasting glucose concentrations were greater for PUFA $<5.5 \%$ than $>5.5 \%$ (estimated 5.33 vs. $5.22 \mathrm{mmol} / \mathrm{L}$ ), and the line graph shows that the genetic effect size was correspondingly greater for low PUFA intake ( 0.30 vs. 0.12 $\mathrm{mmol} / \mathrm{L}$ estimated from their Fig. 1c).

Morcillo et al. [79] reported that HOMA-IR was higher in sunflower oil than olive oil users if they were homozygotes of the minor A-allele of the rs6824447 elongase of long chain fatty acids family 6 (ELOVL6) gene polymorphism but not otherwise $\left(p_{\text {interaction }}=0.001\right)$. Alternatively, Figure 11b (derived from their Fig. 1) suggests average $\log$ HOMA-IR was higher on sunflower oil than olive oil, and that the interaction may be due in part to enhanced genotype differences when HOMA-IR was elevated on sunflower oil.

Ramos-Lopez et al. [80] reported that HOMA-IR increased in association with dietary cholesterol intake in subjects having a high GRS for energy homeostasis $(p<0.001)$ but not in those with a low GRS $(p=0.19)$, resulting in a significant gene-diet interaction $\left(p_{\text {interaction }}\right.$ $=0.002$, their Fig. 2a). However, average HOMA-IR increased with increasing dietary cholesterol intake $(p=0.02)$, and quantile-dependent expressivity would ascribe the interaction to an escalating size of the genetic effect (i.e., the HOMA-IR difference between high and low GRS) as the average HOMA-IR increased with increasing cholesterol intake.

Blanco-Rojo et al. [81] reported that higher saturated fatty acid/carbohydrate ratios were associated with greater increases in HOMA-IR in CC homozygotes than Tallele carriers of the S100 calcium-binding protein A9

Fig. 11. Histograms representing the traditional interpretation of genotypes modifying the effect of diet versus line graphs representing the quantile-dependent expressivity interpretation of a larger genetic effect size at higher average phenotype values for: Phillips et al.'s [78] report that the long-chain acyl CoA synthetase gene (ACSL1) rs9997745 polymorphism modified the effect of polyunsaturated fat intake on fasting glucose concentrations (a); Morcillo et al. [79] report that the elongase of long chain fatty acids family 6 (ELOVL6) polymorphism (rs6824447) modified the effects of olive versus sunflower oil on log HOMA-IR (b); BlancoRojo et al.'s [81] report that the $\$ 100$ calcium-binding protein A9 (S100A9) gene polymorphism modified the effect of the dietary saturated fat/total carbohydrate ratio (SFA/CHO) on HOMA-IR $\left(p_{\text {interaction }}<0.03\right)(\mathbf{c})$. HOMA-IR, homeostatic model assessment of insulin resistance.

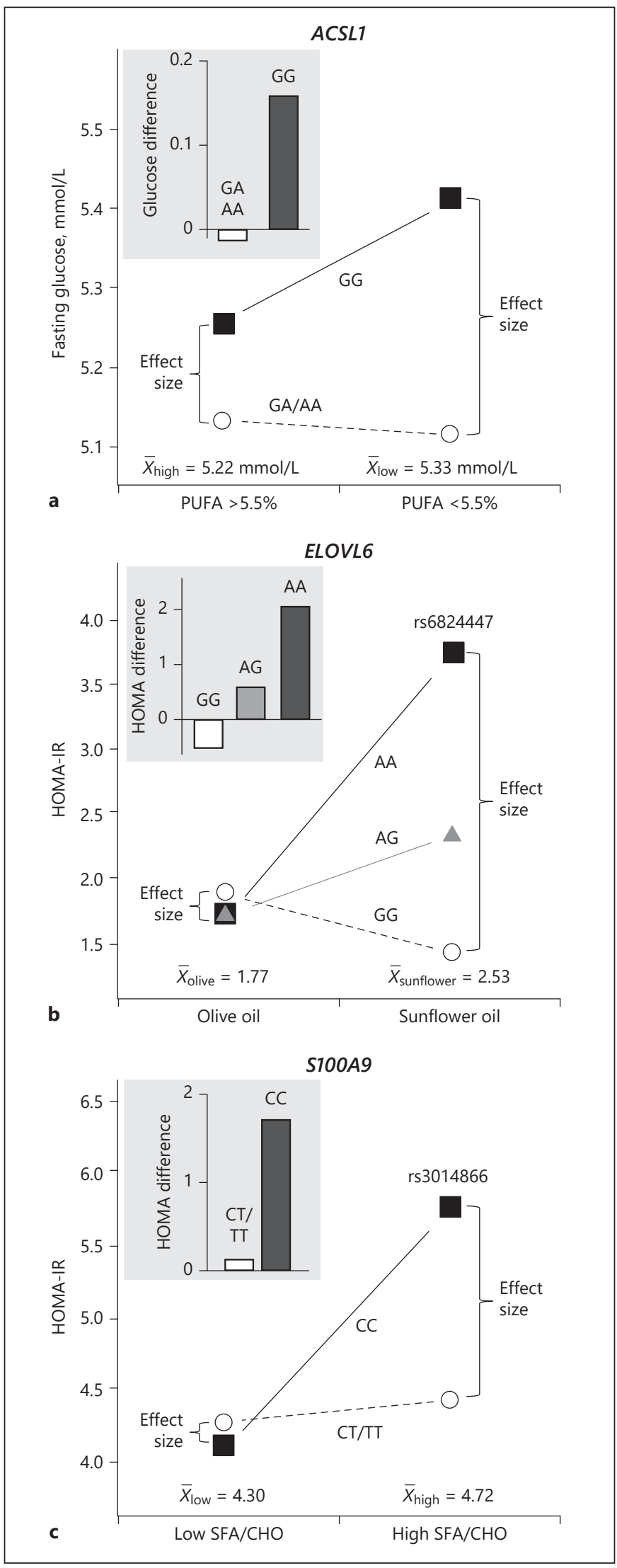


(S100A9) gene (rs3014866) in 3 epidemiological samples: the Coronary Diet Intervention with Olive Oil and Cardiovascular Prevention $\left(p_{\text {interaction }}=0.03\right)$, Genetics of Lipids Lowering Drugs and Diet Network ( $p_{\text {interaction }}=$ 0.02), and the Boston Puerto Rican Health Study $\left(p_{\text {interaction }}=0.03\right)$. Figure $11 \mathrm{c}$, showing the average effects for the combined samples, suggests that the larger effect size at the higher average HOMA-IR levels may have contributed to their findings.

\section{Socio-Economic Status}

Vermeiren et al. [82] reported that fasting glucose heritability was higher in the lowest education $(80 \%)$ vis-à-vis the highest education group $(67 \%, p=0.01)$. These findings are consistent with quantile-dependent expressivity given the higher prevalence of T2DM and other dysglycemia for low socio-economic status due to poor health behaviors and clinical risk factors such as obesity [83].

\section{Limitations}

The primary hypothesis tested is the linear trend in the fasting glucose concentrations over all quantiles. No corrections were made for the number of outcome variables tested. The focus of the manuscript is on the consistency in quantile-dependent heritability across diabetes-related traits. Almost all of the 32 traits examined in Table 2 showed greater heritability at the higher concentrations of the trait distribution (4 exceptions: offspring-parent $\mathrm{HbA} 1 \mathrm{c}, \log$ OGTT glucose, sibling log proinsulin/insulin ratio, log HOMA-B). Our interpretation of the analyses assumes that averaging over repeated measurement provides a reasonable estimate of genetically determined glucose, insulin, etc. The effects of various covariate (beyond age and sex), which might differ between parent and offspring generations, were not considered in these analyses.

Our analyses of the Framingham family sets do not take into account genetic dominance, shared environment, and gene-environment interactions that could affect $h^{2}$ by Falconer's formula [3]. Not all of the genetic variants in the examples presented above have been replicated in GWAS. Consistency with quantile-dependent expressivity does not disprove the gene-environment interaction suggested by others; rather, the phenomenon provides an alternative explanation. Moreover, not all gene-environment interactions involving insulin resistance or beta-cell dysfunction can be explained by quantiledependent expressivity, for example, the glucose difference between $P P A R-\gamma 2$ genotypes was greater after rosiglitazone treatment when concentrations were decreased [84], there were larger genetic effect sizes for OR4S1 rs1483121 ( $\left.p_{\text {interaction }}=0.02\right)$ and ERBB4 rs13390015 $\left(p_{\text {interaction }}=0.02\right)$ in leaner subjects [68], and there were larger differences in fasting insulin concentration between $A P O E$ gene promoter $(-219 \mathrm{G} / \mathrm{T})$ genotypes on high carbohydrate diets than on high fat diets [85]. Alternatively, gene-environmental interactions may arise because glucose homeostasis and environmental factors are genetically co-regulated. Environmental effects on glucose homeostasis may also be quantile-dependent, for example, current adiposity is reported to potentiate the SGA effect on insulin resistance [47]. Among the various genetic variants discovered to date, the proportion of the total glucose, insulin, proinsulin, or HOMA-IR variance explained by any specific SNP is too small to noticeably affect $h^{2}$ [25]. Thus, quantile-specific heritability estimated from the Framingham parent and offspring phenotypes does not dictate the nature of the interaction between any particular genetic variant and its environment.

The gene-environmental interactions discussed above are primarily fan-shaped interactions where the impact of the gene on the phenotype differed by environmental stratum, or the impact of the environment on the phenotype differed by genotype [10]. Quantile-dependent expressivity does not explain crossover gene-environment interactions, where the impact of a gene shows strong opposite effects by environmental stratum or where there are strongly opposing environment-phenotype relationships by genotype. Not only do crossover interactions not fit the model, they may be the consequence of fan-shape interactions being statistically adjusted for the main effects. Although adjustments for confounders and extraneous factors are a prerequisite for publishing gene-environment interactions, such adjustments generally eliminate the information needed to assess whether the phenotype trajectories converge or diverge. In fact, quantile-dependent expressivity contradicts the very model employed for standard covariate adjustment. The large sample size of the Framingham Heart Study provided the statistical power to detect quantile-specific trends that studies of a smaller sample size may lack.

\section{Conclusion}

The thrifty gene hypothesis introduced by Neel [86] attributed the dramatic rise in obesity and T2DM to the selection for genotypes conferring efficient energy metabolism and storage in times of nutrient scarcity. Subsequently its been shown that individuals at the highest percentiles of the BMI distribution experience greater increases in body 
weight due to sedentary lifestyle, low education, diet, and family history than those at the lowest BMI percentiles [87]. Quantile-dependent expressivity hypothesizes that genetic predisposition to higher BMI [4] and hyperglycemia (this paper) is potentiated at higher percentiles of their distributions. Thus, an individual's obesity and hyperglycemia may themselves be major components of their obesogenic and diabetogenic environments, where a cycle of weight gain and higher glycemia cause enhanced susceptibility to obesity and T2DM risk factors, and the recent increases in these conditions in Western societies.

\section{Acknowledgements}

We appreciate the important work of the Framingham Heart Study investigators. The Framingham Study data were obtained from the National Institutes of Health FRAMCOHORT, GEN3, FRAMOFFSPRING Research Materials obtained from the National Heart, lung, and Blood (NHLBI) Biologic Specimen and Data Repository Information Coordinating Center. The hypothesis tested is exploratory and not considered as part of the initial Framingham Study design. The Framingham Study included 3 cohorts. Written informed consent, including consent for genetic analyses, was obtained for all study participants or parent and/or legal guardian if $<18$ years of age.

\section{Statement of Ethics}

Our analyses of these data were approved by Lawrence Berkeley National Laboratory Human Subjects Committee (HSC) for protocol "Gene-environment interaction versus quantile-dependent penetrance of established SNPs (107H021)." LBNL holds Office of Human Research Protections (Federalwide Assurance number
FWA 00006253; approval number: 107H021-13MR20). All surveys were conducted under the direction of the Framingham Heart Study human use committee guidelines, with signed informed consent from all participants or parent and/or legal guardian if $<18$ years of age.

\section{Conflict of Interest Statement}

There are no conflicts of interest to report.

\section{Funding Sources}

This research was supported by NIH Grant R21ES020700 from the National Institute of Environmental Health Sciences, and an unrestricted gift from HOKA ONE ONE.

\section{Author Contributions}

The author is responsible for all statistical analyses and manuscript preparation.

\section{Data Availability Statement}

The data that support the findings of this study are available from the National Heart Lung and Blood Institute's Biospecimen and Data Repository Program. Restrictions apply to the availability of these data, which were used under license for this study. Data are available with the permission of BioLINCC with appropriate human use approval (https://biolincc.nhlbi.nih.gov/home/). The public summary-level phenotype data may be browsed at the $\mathrm{dbGaP}$ study home page phs000007.v30.p11 (https://www.ncbi.nlm.nih. gov/projects/gap/cgi-bin/study.cgi?study_id=phs000007.v30.p11).

\section{References}

1 Wareham NJ, Franks PW, Harding AH. Establishing the role of gene-environment interactions in the etiology of type 2 diabetes. Endocrinol Metab Clin North Am. 2002;31: 553-66.

2 Martin BC, Warram JH, Krolewski AS, Bergman RN, Soeldner JS, Kahn CR. Role of glucose and insulin resistance in development of type 2 diabetes mellitus: results of a 25-year follow-up study. Lancet. 1992; 340:925-9.

3 Falconer DS, Mackay TFC. Introduction to quantative genetics. 4th ed. London: Pearson Education Limited; 2004. ISBN 978-81-317$2740-9$.

4 Williams PT. Quantile-specific penetrance of genes affecting lipoproteins, adiposity and height. PLoS One. 2012;7:e28764.

5 Koenker R, Hallock KF. Quantile regression. J Econ Perspect. 2001;15:143-56.
6 Winer BJ, Brown DR, Michels KM. Statistical principles in experimental design. 3rd ed. New York: McGraw-Hill; 1991.

7 Franks PW, Paré G. Putting the genome in context: gene-environment interactions in type 2 diabetes. Curr Diab Rep. 2016;16: 57.

8 Bouret S, Levin BE, Ozanne SE. Gene-environment interactions controlling energy and glucose homeostasis and the developmental origins of obesity. Physiol Rev. 2015;95:4782.

9 Pearson ER. Personalized medicine in diabetes: the role of 'omics' and biomarkers. Diabet Med. 2016;33:712-7.

10 Dick DM. Gene-environment interaction in psychological traits and disorders. Annu Rev Clin Psychol. 2011;7:383-409.

11 Williams PT. Quantile-specific heritability of total cholesterol and its pharmacogenetic and nutrigenetic implications. Int J Cardiol. 2021; 327:185-92.

12 Williams PT. Gene-environment interactions due to quantile-specific heritability of triglyceride and VLDL concentrations. Sci Rep. 2020;10: 4486.

13 Williams PT. Quantile-specific heritability of high-density lipoproteins with implications for precision medicine. J Clin Lipid. 2020;14:44858.e0.

14 Williams PT. Quantile-dependent expressivity and gene-lifestyle interactions involving high-density lipoprotein cholesterol. Lifestyle Genom. 2021;14(1):1-19.

15 Williams PT. Quantile-dependent expressivity of plasma adiponectin concentrations may explain its sex-specific heritability, geneenvironment interactions, and genotypespecific response to postprandial lipemia. PeerJ. 2020;8:e10099. 
16 Williams PT. Quantile-specific heritability of sibling leptin concentrations and its implications for gene-environment interactions. Sci Rep. 2020;10:22152.

17 Williams PT. Quantile-dependent expressivity of serum C-reactive protein concentrations in family sets. PeerJ. 2021;9:e10914.

18 Williams PT. Quantile-specific heritability of plasminogen activator inhibitor type-1 (PAI1, aka SERPINE1) and other hemostatic factors. J Thromb Haemost. 2021;19(10):255971.

19 Williams PT. Quantile-dependent heritability of computed tomography, dual-energy $\mathrm{x}$-ray absorptiometry, anthropometric, and bioelectrical measures of adiposity. Int J Obesity. 2020;44:2101-12.

20 Williams PT. Quantile-specific heritability may account for gene-environment interactions involving coffee consumption. Behav Genet. 2020;50:119-26.

21 Williams PT. Quantile-specific heritability of intakes of alcohol but not other macronutrients. Behav Genet. 2020;2020(50):332-45.

22 Williams PT. Spirometric traits show quantile-dependent heritability, which may contribute to their gene-environment interactions with smoking and pollution. PeerJ. 2020;8:e9145.

23 Williams PT. Quantile-dependent expressivity of postprandial lipemia. PLoS One. 2020; 15:e0229495.

24 Kannel WB, Feinleib M, McNamara PM, Garrison RJ, Castelli WP. An investigation of coronary heart disease in families. The Framingham offspring study. Am J Epidemiol. 2006; 110:281-90

25 Marullo L, El-Sayed Moustafa JS, Prokopenko I. Insights into the genetic susceptibility to type 2 diabetes from genome-wide association studies of glycaemic traits. Curr Diab Rep. 2014;14:551.

26 Souren NY, Paulussen AD, Loos RJ, Gielen M, Beunen G, Fagard R, et al. Anthropometry, carbohydrate and lipid metabolism in the East Flanders Prospective Twin Survey: heritabilities. Diabetologia. 200;50:2107-16.

27 Dawber TR, Meadors GF, Moore FEJ. Epidemiological approaches to heart disease: the Framingham Study. Am J Public Health. 1951;41:279-86.

28 Splansky GL, Corey D, Yang Q, Atwood LD, Cupples LA, Benjamin EJ, et al. The Third Generation Cohort of the National Heart, Lung, and Blood Institute's Framingham Heart Study: design, recruitment, and initial examination. Am J Epidemiol. 2007; 165: 1328-35.

29 Wilson PW, McGee DL, Kannel WB. Obesity, very low density lipoproteins, and glucose intolerance over fourteen years: the Framingham Study. Am J Epidemiol. 1981;114:697-704.

30 Nelson N. A photometric adaptation of the Somogyi method for the determination of glucose. J Biol Chem. 1944;153:375-80.

31 The Diabetes Control and Complications Trial Research Group. The effect of intensive treatment of diabetes on the development and progression of long-term complications in insulin-dependent diabetes mellitus. N Engl J Med. 1993;329:977-86.

32 World Health Organization. WHO expert committee on diabetes mellitus: second report. Geneva: World Health Organization; 1980.

33 Hanson RL, Pratley RE, Bogardus C, Narayan KM, Roumain JM, Imperatore G, et al. Evaluation of simple indices of insulin sensitivity and insulin secretion for use in epidemiologic studies. Am J Epidemiol. 2000;151:190-8.

34 Karlin S, Cameron EC, Williams PT. Sibling and parent-offspring correlation estimation with variable family size. Proc Natl Acad Sci U S A. 1981;78:2664-8.

35 Gould WW. Quantile regression with bootstrapped standard errors. Stata Technical Bull. 1992;9:19-21.

36 Bergman RN, Finegood DT, Kahn SE. The evolution of $\beta$-cell dysfunction and insulin resistance in type 2 diabetes. Eur J Clin Invest. 2002;32(Suppl 3):35-45.

37 Antuna-Puente B, Disse E, Rabasa-Lhoret R, Laville M, Capeau J, Bastard JP. How can we measure insulin sensitivity/resistance? Diabetes Metab. 2011 Jun;37(3):179-88.

38 Tabák AG, Herder C, Rathmann W, Brunner EJ, Kivimäki M. Prediabetes: a high-risk state for diabetes development. Lancet. 2012;379: 2279-90.

39 Kuzman MR, Medved V, Bozina N, Grubišin J, Jovanovic N, Sertic J. Association study of MDR1 and 5-HT2C genetic polymorphisms and antipsychotic-induced metabolic disturbances in female patients with schizophrenia. Pharmacogenomics J. 2011;11:35-44.

40 He YY, Zhang R, Shao XY, Hu C, Wang CR, $\mathrm{Lu} \mathrm{JX}$, et al. Association of KCNJ11 and ABCC8 genetic polymorphisms with response to repaglinide in Chinese diabetic patients. Acta Pharmacol Sin. 2008;29:983-9.

41 Pei Q, Huang Q, Yang GP, Zhao YC, Yin JY, Song $\mathrm{M}$, et al. PPAR- $\gamma 2$ and PTPRD gene polymorphisms influence type 2 diabetes patients' response to pioglitazone in China. Acta Pharmacol Sin. 2013;34:255-61.

42 Zhou K, Donnelly L, Yang J, Li M, Deshmukh $\mathrm{H}$, Van Zuydam N, et al. Heritability of variation in glycaemic response to metformin: a genome-wide complex trait analysis. Lancet Diabetes Endocrinol. 2014;2:481-7.

43 Díaz M, López-Bermejo A, Sánchez-Infantes D, Bassols J, de Zegher F, Ibáñez L. Responsiveness to metformin in girls with androgen excess: collective influence of genetic polymorphisms. Fertil Steril. 2011;96:208-13.e2.

44 Krentz AJ, Bailey CJ. Oral antidiabetic agents: current role in type 2 diabetes mellitus. Drugs. 2005;65:385-411.

45 Feng Y, Mao G, Ren X, Xing H, Tang G, Li Q, et al. Ser1369Ala variant in sulfonylurea receptor gene ABCC8 is associated with antidiabetic efficacy of gliclazide in Chinese type 2 diabetic patients. Diabetes Care. 2008;31: 1939-44.
46 Barker DJ. The Wellcome Foundation Lecture, 1994. The fetal origins of adult disease. Proc Biol Sci. 1995;262(1363):37-43.

47 Lévy-Marchal C, Czernichow P. Small for gestational age and the metabolic syndrome: which mechanism is suggested by epidemiological and clinical studies? Horm Res. 2006; 65(Suppl 3): 123-30.

48 Jaquet $\mathrm{D}$, Trégouët $\mathrm{DA}$, Godefroy $\mathrm{T}$, Nicaud V, Chevenne D, Tiret L, et al. Combined effects of genetic and environmental factors on insulin resistance associated with reduced fetal growth. Diabetes. 2002;51:3473-8.

49 Eriksson JG, Lindi V, Uusitupa M, Forsén TJ Laakso M, Osmond C, et al. The effects of the Pro12Ala polymorphism of the peroxisome proliferator-activated receptor-gamma2 gene on insulin sensitivity and insulin metabolism interact with size at birth. Diabetes. 2002;51: 2321-4.

50 Kajantie E, Rautanen A, Kere J, Andersson S, Ylihärsilä $\mathrm{H}$, Osmond $\mathrm{C}$, et al. The effects of the ACE gene insertion/deletion polymorphism on glucose tolerance and insulin secretion in elderly people are modified by birth weight. J Clin Endocrinol Metab. 2004;89: 5738-41.

51 Cambien F, Léger J, Mallet C, Lévy-Marchal C, Collin D, Czernichow P. Angiotensin Iconverting enzyme gene polymorphism modulates the consequences of in utero growth retardation on plasma insulin in young adults. Diabetes. 1998;47:470-5.

52 Wing RR, Goldstein MG, Acton KJ, Birch LL, Jakicic JM, Sallis JF Jr, et al. Behavioral science research in diabetes: lifestyle changes related to obesity, eating behavior, and physical activity. Diabetes Care. 2001;24:117-23.

53 Kahn SE, Hull RL, Utzschneider KM. Mechanisms linking obesity to insulin resistance and type 2 diabetes. Nature. 2006;444:840-6.

54 Wang X, Ding X, Su S, Spector TD, Mangino $\mathrm{M}$, Iliadou A, et al. Heritability of insulin sensitivity and lipid profile depend on BMI: evidence for gene-obesity interaction. Diabetologia. 2009;52:2578-84.

55 Ukkola O, Tremblay A, Després JP, Chagnon YC, Campfield LA, Bouchard C. Leptin receptor Gln223Arg variant is associated with a cluster of metabolic abnormalities in response to long-term overfeeding. J Intern Med. 2000; 248:435-9.

56 de Luis DA, Izaola O, Primo D, de la Fuente B, Mulero I, Aller R. The rs1862513 Variant in resistin gene-modified insulin resistance and insulin levels after weight loss secondary to hypocaloric diet. Ann Nutr Metab. 2016; 69:256-62.

57 van Dam RM, Boer JM, Feskens EJ, Seidell JC. Parental history of diabetes modifies the association between abdominal adiposity and hyperglycemia. Diabetes Care. 2001;24:1454-9.

58 Kim M, Jeong S, Yoo HJ, An H, Jee SH, Lee JH. Newly identified set of obesity-related genotypes and abdominal fat influence the risk of insulin resistance in a Korean population. Clin Genet. 2019;95:488-95. 
59 Elosua R, Demissie S, Cupples LA, Meigs JB, Wilson PW, Schaefer EJ, et al. Obesity modulates the association among APOE genotype, insulin, and glucose in men. Obes Res. 2003; 11:1502-8.

60 Uusitupa MI, Karhunen L, Rissanen A, Franssila-Kallunki A, Niskanen L, Kervinen K, et al. Apolipoprotein $\mathrm{E}$ phenotype modifies metabolic and hemodynamic abnormalities related to central obesity in women. Am J Clin Nutr. 1996;64:131-6.

61 Marques-Vidal P, Bongard V, Ruidavets JB, Fauvel J, Hanaire-Broutin H, Perret B, et al. Obesity and alcohol modulate the effect of apolipoprotein E polymorphism on lipids and insulin. Obes Res. 2003;11:1200-6.

62 Grant SF, Thorleifsson G, Reynisdottir I, Benediktsson R, Manolescu A, Sainz J, et al. Variant of transcription factor 7-like 2 (TCF7L2) gene confers risk of type 2 diabetes. Nat Genet. 2006;38:320-3.

63 Li L, Wang J, Ping Z, Li Y, Wang C, Shi Y, et al. Interaction analysis of gene variants of TCF7L2 and body mass index and waist circumference on type 2 diabetes. Clin Nutr. 2020;39:192-7.

64 Jung SY, Sobel EM, Papp JC, Crandall CJ, Fu AN, Zhang ZF. Obesity and associated lifestyles modify the effect of glucose metabolismrelated genetic variants on impaired glucose homeostasis among postmenopausal women. Genet Epidemiol. 2016;40:520-30.

65 Herbert A, Liu C, Karamohamed S, Liu J, Manning A, Fox CS, et al. BMI modifies associations of IL- 6 genotypes with insulin resistance: the Framingham Study. Obesity. 2006; 14:1454-61.

66 Baroni MG, Arca M, Sentinelli F, Buzzetti R, Capici F, Lovari S, et al. The G972R variant of the insulin receptor substrate-1 (IRS-1) gene, body fat distribution and insulin-resistance. Diabetologia. 2001;44:367-72.

67 Manning AK, LaValley M, Liu CT, Rice K, An $\mathrm{P}$, Liu Y, et al. Meta-analysis of gene-environment interaction: joint estimation of SNP and SNP $\times$ environment regression coefficients. Genet Epidemiol. 2011;35:11-8.

68 Manning AK, Hivert MF, Scott RA, Grimsby JL, Bouatia-Naji N, Chen H, et al. A genomewide approach accounting for body mass index identifies genetic variants influencing fasting glycemic traits and insulin resistance. Nat Genet. 2012;44:659-69.

69 Stolerman ES, Manning AK, McAteer JB, Dupuis J, Fox CS, Cupples LA, et al. Haplotype structure of the ENPP1 gene and nominal association of the K121Q missense single nucleotide polymorphism with glycemic traits in the Framingham Heart Study. Diabetes. 2008; 57:1971-7.

70 Boniol M, Dragomir M, Autier P, Boyle P. Physical activity and change in fasting glucose and $\mathrm{HbAlc:}$ a quantitative meta-analysis of randomized trials. Acta Diabetol. 2017;54: 983-91.

71 Waterworth DM, Jansen H, Nicaud V, Humphries SE, Talmud PJ, EARSII Study Group. Interaction between insulin (VNTR) and hepatic lipase (LIPC-514C $>\mathrm{T}$ ) variants on the response to an oral glucose tolerance test in the EARSII group of young healthy men. Biochim Biophys Acta. 2005;1740:37581.

72 Daly ME, Vale C, Walker M, Alberti KG, Mathers JC. Dietary carbohydrates and insulin sensitivity: a review of the evidence and clinical implications. Am J Clin Nutr. 1997; 66:1072-85.

73 Riserus U. Fatty acids and insulin sensitivity. Curr Opin Clin Nutr Metab Care. 2008;11: 100-5.

74 Huang T, Beaty T, Li J, Liu H, Zhao W, Wang Y. Association between dietary fat intake and insulin resistance in Chinese child twins. Br J Nutr. 2017;117:230-6.

75 Mohan V, Sudha V, Radhika G, Radha V, Rema M, Deepa R. Gene-environment interactions and the diabetes epidemic in India. Forum Nutr. 2007;60:118-26.

76 Dziwura J, Bińczak-Kuleta A, Miazgowski T, Ziemak J, Widecka K. The associations between G972R polymorphism of the IRS-1 gene, insulin resistance, salt sensitivity and non-dipper hypertension. Hypertens Res. 2011;34:1082-6.

77 Smith CE, Arnett DK, Corella D, Tsai MY, Lai CQ, Parnell LD, et al. Perilipin polymorphism interacts with saturated fat and carbohydrates to modulate insulin resistance. Nutr Metab Cardiovasc Dis. 2012;22:449-55.

78 Phillips CM, Goumidi L, Bertrais S, Field MR, Cupples LA, Ordovas JM, et al. Gene-nutrient interactions with dietary fat modulate the association between genetic variation of the ACSL1 gene and metabolic syndrome. J Lipid Res. 2010;51:1793-800.

79 Morcillo S, Martín-Núñez GM, Rojo-Martínez G, Almaraz MC, García-Escobar E, Mansego ML, et al. ELOVL6 genetic variation is related to insulin sensitivity: a new candidate gene in energy metabolism. PLoS One. 2011;6:e21198.

80 Ramos-Lopez O, Riezu-Boj JI, Milagro FI, Cuervo M, Goni L, Martinez JA. Interplay of an obesity-based genetic risk score with dietary and endocrine factors on insulin resistance. Nutrients. 2019;12:33.

81 Blanco-Rojo R, Delgado-Lista J, Lee YC, Lai CQ, Perez-Martinez P, Rangel-Zuñiga O, et al. Interaction of an S100A9 gene variant with saturated fat and carbohydrates to modulate insulin resistance in 3 populations of different ancestries. Am J Clin Nutr. 2016;104:508-17.

82 Vermeiren AP, Bosma H, Gielen M, Lindsey PJ, Derom C, Vlietinck R, et al. Do genetic factors contribute to the relation between education and metabolic risk factors in young adults? A twin study. Eur J Public Health. 2013;23:986-91.

83 Wikström K, Lindström J, Tuomilehto J, Saaristo TE, Korpi-Hyövälti E, Oksa H, et al. Socio-economic differences in dysglycemia and lifestyle-related risk factors in the Finnish middle-aged population. Eur J Public Health. 2011;21:768-74.

84 Kang ES, Park SY, Kim HJ, Kim CS, Ahn CW, Cha BS, et al. Effects of Pro12Ala polymorphism of peroxisome proliferator-activated receptor gamma2 gene on rosiglitazone response in type 2 diabetes. Clin Pharmacol Ther. 2005;78:202-8.

85 Moreno JA, Perez-Jimenez F, Marin C, PerezMartinez P, Moreno R, Gomez P, et al. The apolipoprotein E gene promoter $(-219 \mathrm{G} / \mathrm{T})$ polymorphism determines insulin sensitivity in response to dietary fat in healthy young adults. J Nutr. 2005;135:2535-40.

86 Neel JV. Diabetes mellitus: a "thrifty" genotype rendered detrimental by "progress"? Am J Hum Genet. 1962;14:353-62.

87 Williams PT. Evidence that obesity risk factor potencies are weight dependent, a phenomenon that may explain accelerated weight gain in western societies. PLoS One. 2011;6:e27657. 